\title{
Non-parental care in childhood and adult outcomes: double whammy for minority children?
}

Amanda Sacker ${ }^{1}$

Emily T Murray ${ }^{1}$

Barbara Maughan ${ }^{2}$

Rebecca E Lacey ${ }^{1}$

${ }^{1}$ International Centre for Lifecourse Studies in Society and Health (ICLS),

Department of Epidemiology and Public Health, University College London, 1-19 Torrington Place, London, WC1E 6BT, UK

${ }^{2}$ MRC Social, Genetic and Developmental Psychiatry Centre, King's College London, 16 De Crespigny Park, London, SE5 8AF, UK 


\section{Abstract}

\section{Background}

Children who spent time in non-parental care report poor outcomes in many aspects of their later lives on average, but less is known about differences by ethnicity. We examined whether the health, socioeconomic, family, and living arrangements of adults who had been in non-parental care across the first three decades of adult life varied by ethnicity (White, Black, South Asian).

\section{Methods}

We used longitudinal data from the Office for National Statistics Longitudinal Study (LS). Participants were aged $<18$ years and had never been married at baseline of each census year from 1971-2001 $(n=672,648)$. Separately for each adult follow-up age group (20 to $29 ; 30$ to $39 ; 40$ to 49 ), multilevel regression models were used to compare socioeconomic, family, and living arrangements by non-parental care and ethnicity interactions.

\section{Results}

Adverse adult outcomes following an experience of non-parental care were conditional on the interaction of non-parental care with ethnicity, mainly in the socioeconomic domain. More negative adult outcomes among the ethnic minority groups following non-parental care in childhood were not found consistently: for some outcomes the White group had poorer outcomes; South Asian individuals had better outcomes than Black people who had been in non-parental care but the within-ethnic group differences were smaller for Black than for South Asian children; and findings differed across the lifespan from early to mid-adulthood as work and family lives evolved.

\section{Conclusion}

We uncovered much complexity, with minority ethnicity moderating the non-parental care to adult outcomes relationship in both positive and negative ways. Previous work that has sampled children from the population with experience of non-parental care provides incomplete evidence from which to base policy decisions.

\section{Keywords:}

ethnicity; child; non-parental care; follow-up study; prospective; census 


\section{Introduction}

There are well-known ethnic variations in non-parental care placement numbers in the UK and elsewhere [1-6]. Ethnic minority groups such as Black African and Black Caribbean are overrepresented amongst children in residential care [4], foster care [5], and kinship care [6] and South Asian groups are underrepresented [2]. Some find Black children's over-representation can be explained by deprivation [1], yet others highlight discrimination or bias [7, 8]. Bywaters and colleagues [9] distinguish between these and artefactual factors such as data quality when theorising ethnic inequalities in child welfare, finding evidence supporting deprivation, discrimination and bias. Both in the United Kingdom (UK) and United States (US), an "Asian paradox" has been noted: Despite coming from more deprived backgrounds on average (a common predictor of non-parental care), South Asian children are under-represented in care statistics [2, 9]. Placements in out-of-home care are also said to follow the "Inverse Intervention Law", whereby interventions are more common for children living in less deprived areas than children in more deprived areas $[10,11]$. All this points to the complexity in understanding ethnic inequalities in non-parental care and its consequences.

Children in non-parental care are at higher risk of adverse outcomes later in life [12-23]. This includes outcomes such as poorer mental $[12,15,16,18,22]$ and physical health [15, 20-22], less education and lower qualifications $[14,15,22]$, employment and socioeconomic position $[14,15$, $22]$, relationships and family formation [13, 14, 17] and living conditions [15].

In addition, some studies find ethnic minority groups who have been in non-parental care at increased risk of adverse adult outcomes compared with the White majority care-experienced group $[5,24-31]$. However, there are a number of difficulties in interpreting these findings. First, it is wellknown that there are ethnic inequalities in outcomes in adulthood more generally [32-37]. Most research on ethnic differences in outcomes after care has sampled care-experienced children only [24-29, 31, 38, 39]. Without a comparator group of children in parental care, we cannot rule out confounding as an explanation for the excess risk to minority children in non-parental care. Could the observed ethnic inequalities in outcome associated with placements in care simply be a consequence of ethnic inequalities in adult outcomes irrespective of whether they are care experienced or not? Second, most research in this area is retrospective $[5,24,26]$ or only follows-up children for a few years [30]. Both these designs have disadvantages which can affect reliability and hence their usefulness for policy. Third, many of the studies have small samples, are unrepresentative or collect qualitative data which tends to involve small non-random samples [24, $25,40]$. Again, reliability of findings is an issue. Fourth, almost all the published studies are located in 
the US where ethnicity and race have different meanings and implications from those in the UK [5, $25-29,31,38,39,41]$. We do not know if we can extrapolate their findings to the UK context. Therefore, this study adds to the literature in several ways. First, by taking an intersectional approach [42]. Intersectionality theory originally wanted to develop understandings of ethnic and gender-based inequalities by arguing that Black African women, for example, are affected by mutually created ethnic and gendered influences, and that inequalities cannot be understood by treating ethnicity and gender as distinct subjects of analysis. From an intersectional perspective, ethnicity and non-parental care interact, so that ethnicity changes the experiences of care, and nonparental care changes the experience of ethnicity. The two sources of inequality cannot be separated out, they are not mutually exclusive categories. Inequality in adult outcomes evolves over time as ethnicity influences both decisions about non-parental care as well as experiences of care. In turn, the choices made by different ethnic groups as they transition to adulthood and beyond are affected by the constraints experienced by those living apart from their parents.

In addition, this work is based on data from a large representative study of England and Wales, namely the Office of National Statistics (ONS) Longitudinal Study (LS). The LS, started in 1971, contains linked census and life events data for a 1\% sample of the population of England and Wales. This makes the LS the largest longitudinal study of these populations, containing records on approximately 1 million people, collected over the 40 years of the study. The advantages of the LS are that in combination with the very large sample size, it has low levels of attrition, making it ideal for research into small and possibly hard-to-reach subgroups of the population. Using these data, we hypothesise that 1) Adverse adult sociodemographic and health outcomes following an experience of non-parental care will be conditional on the simultaneous intersection of non-parental care with ethnicity; and 2) More negative adult outcomes will be observed following non-parental care in childhood for ethnic minority children, especially Black children.

\section{Methods}

\section{Data}

The Office for National Statistics Longitudinal Study (LS) is a 1\% representative sample of the population of England and Wales, drawn initially from respondents to the 1971 census who were born on one of four dates in the calendar year [43]. New members - newly born or immigrants - are added to the LS if they have the same four birthdates. Similar $1 \%$ samples have also been drawn from the 1981, 1991, 2001 and 2011 censuses. The LS has linked records for each census after LS 
members were first sampled to create a longitudinal dataset. Census data are also collected on the LS members' co-residents, but these are not linked and are cross-sectional only. LS members' data from birth, death and cancer registers have been added to the LS since 1971.

\section{Inclusion and exclusion criteria}

\section{Main exposures}

The main exposures were ethnicity, experience of non-parental care and their interaction. Sensitivity analyses (below) used a secondary exposure, whether UK born or not, to replace ethnicity.

\section{Care type}

For each census from 1971 to 2001, household grid and residential type data was used to classify dependent children as either: (1) living with a parent (including adoptive parents), (2) living with an adult relative, (3) living with an unrelated family (fostered or informally with a family friend), or (4) living in residential care (a children's home or place of detention) on the respective census day. Those living in other types of communal establishment (e.g. hotel, hostel, hospital) at the time of the census were excluded from the sample. For the main analyses, non-parental care types (types 2-4) were combined.

\section{Ethnicity}

Information on ethnicity is only available from 1991, so for LS children in the 1971 and 1981 censuses, ethnicity was extrapolated from their responses in later censuses. The question wording changed in each census. In 1991, there were 7 boxes to tick, with an 'any other' option where people could write in their ethnicity using their own words. People were instructed to either tick the group to which they felt they belonged or use the 'any other' option if they belonged to mixed or multiple ethnic groups. In 2001, people were asked to choose one of 5 sections (White; Mixed; Asian or Asian British; Black or Black British; and Chinese or other ethnic group), and then select from 2-3 boxes within the section or use the option to write in their ethnicity. In 2011, the question changed again with new labels for the 5 sections (White; Mixed/multiple; Asian/Asian British; Black, African/Caribbean/Black British; Other ethnic group) and an expanded selection of 13 boxes in total to tick and again, an option to write in their ethnicity within each section.

The LS ethnicity data has been derived from these questions to create 35 ethnic identities in 1991; 695 identities combined into 16 groups in 2001; and 760 identities combined into 23 groups in 2011. We reduced the number of groups to 4: 0 White; 1 Black (African, Caribbean, Black British, mixed Black/other); 2 South Asian (Indian, Pakistani, Bangladeshi, mixed South Asian/other); and 4 Other 
(including e.g., Chinese, Arab, other Asian, Travellers, South American). Because the Other category is so heterogeneous, we dropped those in this category from the analysis.

\section{Non-UK born}

A census question on country of birth recorded whether LS children were born in the UK (0) or elsewhere (1).

\section{Outcomes}

Health and social outcomes are taken from the 1981 to 2011 censuses. So, LS members from the 1971 census can have outcomes at 10-, 20-, 30- and 40-year follow-up whereas LS members from the 2001 census have outcomes at the 10-year follow-up only.

\section{Health}

Two health indicators were assessed at both the 2001 and 2011 censuses: self-rated health (SRH) and limiting long-term illness (LLTI). For SRH, in the 2001 census a question asked respondents "over the last 12 months would you say, your health has on the whole been: good, fairly good or not good?" For the 2011 census, the SRH question was changed to "How is your health in general" and the categories were expanded to five options: very good, good, fair, bad and very bad. For both years, responses were dichotomised into 0 'good' versus 1 'not good' SRH (categories fairly good/ not good in 2001; fair/ bad/ very bad in 2011). For LLTI, the 2001 census question asked whether the respondent had "a long-term illness, health problem or disability which limits your daily activities or the work you can do". For the 2011 census, the question was changed to, "Are your day-to-day activities limited because of a health problem or disability which has lasted, or is expected to last, at least 12 months: yes-limited a lot, yes-limited a little, or no". The responses were dichotomised into 0 not limited vs. 1 limited.

\section{Education}

Highest qualification level was harmonised across census years into the categories $0: \geq 18$ years qualifications (A levels or higher); and 1: $<18$ years qualifications.

\section{Work}

Those who are $\geq 16$ years old are asked if they are currently working and if not the number of years since they last worked (census year 1991) or if they had no paid work in the last 10 years (20012002). From these responses, we derived a binary variable indicating whether the individual was long-term non-employed (i.e. $\geq 10$ years, value 1 ) or not (value 0 ). Current employment status is a categorical variable indicating whether the person was working (0) unemployed (1), in education (2) 
or otherwise out of the labour force (3) at the time of the census. Social class is measured using the 3-category version of the National Statistics Socioeconomic Classification (NS-SEC): 0:

Managerial/professional; 1 Intermediate occupations; 2 Routine occupations [43]; plus 3: a Not Known category if the LS member did not give sufficient details of their current or last held job to give them a social class.

\section{Living arrangements}

Housing tenure indicates whether the home is owner occupied (0), rented (1), or other (2). Overcrowding was defined as a ratio $>1.5$ of the number of persons in the household to the number of rooms ( 0 vs. 1 , overcrowded). Living alone is a binary indicator derived from questions on household composition ( 0 no; 1 yes).

\section{Relationships}

Marital status is defined as legally married (0); divorced/widowed (1); or single (3). For women only, the LS is linked to the Births Registration form, from which number of children and age at first child was derived.

\section{Covariates}

\section{Demographic variables}

Country of birth, childhood census, childhood age in years and gender ( 0 male; 1 female) were taken from the census in which an LS child was observed. Country of birth was collapsed into UK-born (0) and born outside the UK (1). Childhood censuses were coded 0: 1971; 1: 1981; 2: 1991; and 3: 2001. For the main analyses, non-UK born was included as a covariate.

\section{Childhood socioeconomic variables}

Data on the socioeconomic environment in childhood were only available for children observed in private households. For children in residential care, data were taken from the previous or subsequent census if satisfying the criterion of being a dependent child living with a parent at that time. Otherwise, an extra "Missing" category was assigned.

Head of household $(\mathrm{HoH})$ social class was measured using the 3-category version of the NS-SEC described above. Educational level identified whether the $\mathrm{HoH}$ had $18+$ years qualifications or not, as above. $\mathrm{HoH}$ employment indicated if they were currently in work (0) or not (1). HoH marital status was collapsed into 3 categories: legally married (0), divorced/widowed (1) or single (2). Instructions in the 1971-1991 censuses tell separated respondents to choose married or re-married categories; information on cohabiting is only available from 2001. 


\section{Analysis}

Data from census years 1971 to 2001 were pooled and linked to follow-up records from 1981 to 2011. The background characteristics of the analytical sample and those excluded due to loss-to follow-up or item non-response are shown in online Supplementary tables S1. The distribution of the variables in the analysis sample are very similar to that in the full data sample. The incomplete sample distributions show that most data were missing on $\mathrm{HoH}$ social class and that those excluded were more likely to be from more disadvantaged socioeconomic households. There were 672,648 observations in total in the analysis sample.

The sociodemographic characteristics of children in parental and non-parental care by ethnic group were compared using independent samples t-tests or non-parametric equivalents, as appropriate. Repeated measure regression models were fitted within the Stata GSEM framework [44], with standard errors adjusted for clustering of 1 to 2 census records in childhood for each LS child. Models for the set of outcomes were estimated when measured during three follow-up periods: when aged $20-29$ years $(N=310,381), 30-39$ years $(N=217,969)$ and $40-49$ years old $(N=144,329)$. The number of observations varied across outcomes but were at or close to the maximum within follow-up except for self-rated health and limiting long-term illness where availability was restricted to the most recent censuses, and age at first birth which was restricted to parous women only. Model 1 estimated the ethnicity by non-parental care interaction without any covariates; model 2 controlled for all the covariates outlined above plus adult age in years.

Since main effects are reported elsewhere [45], we estimated and report average marginal effects for each outcome. For linear outcomes, this is the average of the difference between estimated values on the outcome if each LS member had been in parental or non-parental care by ethnic group, leaving all other covariate values unchanged. For non-linear outcomes, average marginal effects give the average of the difference in the probability of the outcome if each LS member had been in parental or non-parental care by ethnic group, again leaving all other covariate values unchanged. We report the significance of the care type by ethnicity interaction before and after applying the Holm-Bonferroni correction for multiple testing [46].

A sensitivity analysis was carried out: Model 2 was re-estimated with minority ethnicity replaced by born in the UK vs. not and ethnicity replacing UK-born in the list of covariates.

\section{Results}

The sociodemographic characteristics of children in parental and non-parental care by ethnic group are shown in table 2. Black and South Asian children were more likely to have been in non-parental 
care than White children, as were children born outside the UK. No gender imbalance was seen. Children in care lived in households where the $\mathrm{HoH}$ was more likely to be in the Routine than the Managerial/Professional social class, with poorer qualifications, non-employed and unmarried (either single or divorced/widowed).

Descriptive data on differences in adult outcomes by ethnicity and care type (table 3 ) show no difference in self-rated health by ethnic group in the non-parental care group but a suggestion that Black adults in the parental care category were more likely to report poor self-rated heath. By contrast, although differences in limiting long-term illness among the parental care category mirrored those for self-rated health, White care-experienced adults reported more limiting longterm illness than the ethnic minorities. On average, White adults had the lowest qualifications irrespective of care type but there was no consistent pattern across care types for the minority groups. The minority groups were less likely to be in work if they had been in parental care but more likely to be employed if in non-parental care. Black adults were less commonly owner-occupiers regardless of care type and South Asians more often in overcrowded accommodation and least often living alone in adulthood. Black adults were more often single irrespective of care type and South Asian women were on average older when they had their first child.

The differences reported above do not consider how sociodemographic background could account for some of the findings. We next report average marginal effects from models that adjust for background characteristics (tables 4-6 for follow-ups at 20 to 29 years, 30 to 39 years and 40 to 49 years old. The final column in each table gives the significance of the ethnicity by care type interaction, while those outcomes highlighted in bold show those interactions that are still significant following adjustment for multiple testing. The average marginal effects address the question "if we could just change whether someone had been in care or not, what would have been the outcome?" A positive effect shows that a categorical outcome would have been more common, or a continuous outcome had a higher mean value, if everyone in the ethnic group had been in nonparental care. Supplementary tables S2-S4 provide the coefficients for the interaction terms in each model.

\section{Age 20-29 year follow-up}

When LS members were in their 20s, non-parental care was associated with a higher probability of having poorer qualifications among the White (10\% difference) and South Asian (8\%) ethnic groups but not the Black group (table 4). Being less likely to be employed and more likely to be unemployed or out of the labour force for reasons other than education was predicted for White adults if they had a history of non-parental care, whereas care-experienced Black adults were predicted to be less commonly unemployed and South Asian adults $5 \%$ more likely to be unemployed and $6 \%$ less likely 
to be in education than their same-ethnicity peers. Consistent with these findings, non-parental care among White and South Asian adults was linked to a more disadvantaged social class than their same-ethnicity peers, but no social class differences associated with care type were predicted for Black adults. Both White and Black adults were predicted to have a lower probability of home ownership and a higher probability of renting or being in other forms of accommodation if they had a history of non-parental care, while only a lower probability of being in other accommodation was predicted for South Asian adults. There was also a suggestion of differences in the average marginal effect of care across ethnic groups with White and South Asian adults more likely to be married and White adults more likely to be long-term non-employed in their 20s, but these were not significant after adjustment for multiple comparisons. There was no difference in the probabilities of adverse health outcomes, overcrowding, or living alone by care type across ethnic groups. Neither was there any difference in mean age at first child or mean number of children for women associated with care type by ethnic group.

Age 30-39 year follow-up

At the 30-39 year follow-up, non-parental care predicted the same difference in the probability of poor qualifications among White adults, and no difference among Black adults, as in their 20s (table 5). However, there was a suggestion that the difference widened among South Asians in nonparental care ( $\Delta 15 \%$ compared with $\Delta 8 \%$ at the $20-29$ year follow-up). Unlike in their 20 s, there was only a suggestion of differences in employment status by ethnic group, but social class differences remained the same, with non-parental care among White and South Asian adults related to a more disadvantaged social class, but no social class differences associated with care type predicted for Black adults. There were also no longer any ethnic differences in housing tenure associated with care type. Instead, White adults in their 30s had a higher probability and South Asian adults a lower probability of living alone if care-experienced compared with their same-ethnicity peer group, albeit with small changes given the low rates of living alone overall. The lack of ethnic differences associated with care type for the health, overcrowding and fertility outcomes remained. Moreover, there was no longer any suggestion of differences for marital status.

\section{Age 40-49 year follow-up}

Results at the 40-49 year follow-up for qualifications, social class and living alone were consistent with the 30-39 year follow-up (table 6), but with some qualitative variations. There was a suggestion that with the expansion in further education, both White and South Asian adults who had been in non-parental care had acquired more qualifications as the difference between those with and without a history of care is predicted to have narrowed. The same difference in the probability of 
being in the most advantaged social class was still evident for the South Asian group but there was a suggestion of upward intra-individual social mobility for the White group. There was a hint of new differences in the average marginal effect of care across ethnic groups emerging as individuals aged. There was a higher probability of limiting long-term illness associated with non-parental care among the White adults that was not observed among the ethnic minority groups. White adults were also predicted to have a lower probability of being married and a higher probability of being divorced in their 40s associated with being in non-parental care as a child. By contrast, South Asian adults were predicted to have a higher probability of being married. Marital status throughout adulthood among Black adults was not predicted to vary by care type.

\section{Sensitivity analyses}

\section{Born in or outside the UK}

Table S5 presents the average marginal effects for the models with a UK-born and non-parental care interaction term. Results are broadly similar to those presented earlier by ethnicity but there are subtle differences unique to migration into the UK. These differences need to be interpreted in the light of the changing migration waves to the UK from 1971 to the present day.

There was no difference in the probability of poor qualifications associated with non-parental care $(\approx$ $9 \%$ increase) by UK-born or not at the 20-29 year and 30-39 year follow-ups. But at the 40-49 year follow-up, the difference for UK-born adults had reduced to 3 percent while the difference for non UK-born had increased to 17 percent.

As for the average marginal effects by ethnicity, employment status at the 20-29 year follow-up showed a disadvantage for UK-born adults if they had been in non-parental care in childhood but there was little evidence that employment status for adults born outside the UK differed by care type apart from a suggestion that adults born outside the UK were predicted to have a lower probability of being in education if in non-parental care in childhood.

The association between non-parental care and social class differed by ethnicity at all three followups. But, as for employment status, the association between non-parental care and social class only differed by UK-born status at the 40-49 year follow-up. The average marginal effects show that UKborn adults were predicted to be in less advantaged social positions than their peers born elsewhere if previously in non-parental care. For adults born outside the UK, those previously in non-parental care were predicted to be in more advantaged social positions than their peers but less likely to have reached the managerial/ professional social class.

Like the findings by ethnicity, there were only differences in housing tenure associated with nonparental care by non UK-born status at the 20-29 year follow-up but the details conflicted. Ethnic 
minority groups had a lower probability of being owner-occupiers if in non-parental care while non UK-born young adults had similar chances of owning their home irrespective of care type.

Unlike the findings by ethnicity, care type differences by country of birth were observed for the relationship and fertility outcomes. Non UK-born adults in their 30s were predicted to have a lower probability of divorce or widowhood if they had been in non-parental care. Non UK-born women were also predicted to have fewer children if they had been in care with the difference greater in magnitude that for UK-born women compared with their peers.

\section{Discussion}

\section{Summary of principal findings}

Our first hypothesis was that adverse adult sociodemographic and health outcomes following an experience of non-parental care would be conditional on the interaction of non-parental care with ethnicity. This was largely supported. From 36 models (12 outcomes by 3 follow-up periods), we found 75 percent had an interaction of non-parental care with ethnicity. After applying an adjustment for multiple testing, 10 models with interaction terms were retained, suggesting that ethnicity did not universally moderate the impact of a history of non-parental care on adult outcomes.

The second hypothesis was that more negative adult outcomes would be observed among the ethnic minority groups following non-parental care in childhood. The results showed a far more nuanced picture than the hypothesis would suggest. It was far from the case that following time in nonparental care, more negative adult outcomes were predicted for ethnic minority groups compared with the White majority. First, moderation of the impact of non-parental care by ethnicity was almost exclusively found in the socioeconomic domain or in downstream outcomes to socioeconomic position. Second, the relationship between non-parental care and ethnicity differed across the ethnic groups that we studied: a general observation was that South Asian non-parental care-experienced individuals fared better than Black people who had been in non-parental care. Third, for both the Black and South Asian groups, children in non-parental care were predicted to have more similar outcomes to their peers brought up in parental care. Instead, it appeared that White children were more likely to be affected by experiences of non-parental care. Fourth, there were smaller within-ethnic group differences in the relationship of non-parental care with outcomes among Black than South Asian children. Fifth and finally, findings differed across the lifespan from early to mid-adulthood as work and family lives evolved. 


\section{Results in relation to other studies}

Comparison with the literature is hampered by a dearth of studies situated in the UK. Most of the research on ethnicity and non-parental care comes from US samples. It is unlikely that Black Americans experience the same intended or unintentional discrimination as Black people living in Britain with respect to their non-parental care or their adult employment prospects, for example. Similarly, although our South Asian group is somewhat heterogeneous, with the Pakistani and Bangladeshi population more socioeconomically deprived than the Indian population in Britain, South Asians are unrepresented as a unique group in almost all US studies that typically only separate Black and Hispanic groups, with South Asians included in an 'Other' category. However, Black American and Hispanic people in the US do share the common experience of being in the minority in their country as do Black and South Asian citizens in Britain.

Our first finding was that moderation of the impact of non-parental care by ethnicity was almost exclusively found in the socioeconomic domain or in downstream outcomes to socioeconomic position. This was mirrored in the US, with no differences in the health domain by ethnicity $[5,26$, $28,38,39]$. We did not find any literature on marriage to compare with our findings of a tendency for White adults to be more likely to divorce if they had been in non-parental care. However, while a previous study reported that Black women who had been in non-parental care had fewer children than White women with the same childhood experience [25], we were able to show that this difference could be attributed to independent associations with ethnicity and non-parental care and not to their interaction. Similarly, the assumption that Black mothers in non-parental care are most at risk of having children at a younger age in both the UK and US $[25,26,40]$, was not upheld in our analysis. In fact, when a longer-term perspective is taken and a comparison with the general population of parous women is made, we observe that ethnic minority mothers had children at a younger age independent of care in childhood, and once this was considered, women had children later after non-parental care in childhood and again there was no evidence of intersectionality. However, we acknowledge that there may be a sub-group of women who had teenage pregnancies although the age 20-29 year follow-up findings did not support this suggestion.

Our second finding was that Black non-parental care-experienced adults fared worse than South Asian individuals who had been in non-parental care. This was also seen in a report by Barn and colleagues [24] on a mixed-methods study of life following non-parental care in a different sample in England: In the quantitative arm, Black young adults had lower qualifications than their South Asian counterparts and were more likely to be unemployed and living alone. Moreover, our findings show that when comparisons are possible with a general population sample, the finding that following 
non-parental care Black young adults were more likely to return to further education was not a reflection of 'bouncing-back' but a common experience for Black adults regardless of their care in childhood.

Third, we found that White adults in their 20s were more likely to be affected by experiences of nonparental care than minority children in terms of their qualifications. This was also highlighted in one study from the US and one other study from the UK $[24,26]$. However, not all studies found the same White disadvantage in employment and social class that we observe, with some reporting no difference across ethnic groups [31], and others that there was a White advantage following a history of non-parental care [26]. Location, sampling and methodology might account for these contrasting findings.

Fourth, Black children in non-parental care had more similar outcomes to other Black children in most domains of adult functioning compared with the within-South Asian group differences in outcomes. We could find no other studies of Black experiences of non-parental care in a general population sample to support this inference. From table 3, the reason for the contrast between these two minority groups lies in the fact that the Black group in parental care fared more poorly in adulthood than the South Asian group in parental care, whereas for those in non-parental care the South Asian group fared more poorly in adulthood than the Black group.

Our fifth observation is that findings changed across the lifespan from early to mid-adulthood as work and family lives evolved. This was observed for social class, as people tend to be upwardly mobile from their 20s to middle age; for educational qualifications, where there was evidence of returning to education; and for living alone, where changing circumstances or individual preference led more people to live alone as they moved through the life span. There were only small signs of care gaps narrowing with age for the minority groups (e.g., education, unemployment and housing tenure for the Black group), but also signs that some gaps widened (e.g., qualifications for the South Asian group). Since we found no studies on long-term outcomes for ethnic minorities in nonparental care, we cannot discount the view that these signs are artefactual.

Finally, the sensitivity analysis showed that research on the fate of migrants to the UK who find themselves in non-parental care does not mirror that of ethnic minority groups, and the findings should not be extrapolated from one situation to the other. More specifically, migrants and nonmigrants to the UK differed in the association of non-parental care with adult outcomes in the family domain whereas the ethnic minority groups were similar to the White group in this domain; gaining further qualifications in adulthood following non-parental care was restricted to UK-born individuals with gaps emerging in the 40s for non-UK born persons; and consistent with the findings for 
qualifications, social class differences emerged in the 40-49 year follow-up with non-UK born people with non-parental care experiences being far less likely to be in a managerial/professional class than non-UK born people with a history of parental care. A more in-depth study of migrants in nonparental care might help elucidate the fiscal and residency policies that might be exacerbating social inequalities. A Swedish study of employment status up to age 35 following foster care in childhood found little evidence for intersectionality between foster care and being an immigrant [47]. Perhaps their study's limited follow-up accounted for the lack of corroboration. Another study of the British Child Migrant cohort in Australia found that many experienced difficulties during the transition to independent living, especially in relation to continuing education [48]. They also reported lifelong mental and physical health issues for many former child migrants compared with other general population samples in Australia. Our finding of no difference in the health measures between the UK and non-UK born in non-parental care contrasts with theirs, although many substantive and methodological differences between our study and theirs may account for this.

\section{Strengths and limitations}

Some limitations must be acknowledged. In common with most previous research, ethnicity was only measured quite crudely despite our large sample. We were unable to distinguish between Black African and Black Caribbean children, or between Indian, Bangladeshi and Pakistani children, and other evidence suggests that findings may well vary across these groups. It is also possible that the experiences of mixed White and minority ethnic groups could differ. We have assumed that their identity and life experiences will be more like those of the minority group than the White majority but acknowledge that this may no longer be the case in the population today.

A major disadvantage of using the LS dataset is a lack of data on reason(s) for non-parental care and family characteristics prior to children being placed in non-parental care, which are both likely to correlate with adult functioning and selection into non-parental care. Factors influencing selection into different types of non-parental care must also be acknowledged which could affect the interpretation of the findings. Overall, children will have been placed in residential care only if they were unable to have been placed elsewhere, usually because their health or behaviour precluded placement in a family setting. Informal kinship care is more normative for some ethnic minorities than the White majority. Placement in kinship care may have been excluded as an option due to concerns about parental and wider family circumstances: Selection into kinship care suggests children might already have had a better environment for positive social development. Unfortunately, even with the larger sample size that the LS provides, splitting the data by ethnicity 
and non-parental care type resulted in cell sizes that substantially reduced the power to detect the ethnic variation that we were interested in (data not shown).

Another disadvantage of using census data is that they are only available every 10 years. Therefore, we were not able to identify the exact age when children were placed in non-parental care, nor for how long. Moreover, we were unable to identify children with and without local authority care orders which might alter the experience of non-parental care within ethnic minority groups. As in any longitudinal study, sample attrition occurred, albeit at lower levels than reported elsewhere [22, 49]. There were indications in our data that loss to follow-up was greater in the non-parental care group, suggesting that some bias may have been introduced into the estimates. Finally, as in any study using routine self-reported data, we cannot rule out the possibility of measurement error. However, the study has many strengths. This longitudinal study had repeated prospective collection of non-parental care experiences, health and social outcomes, and covariates across four decades. Coupled with the data being nationally representative, this allowed us to investigate whether adults who had a history of non-parental care had different outcomes up to 30 years later from individuals without any experience of care. We could estimate differences throughout early to mid-adulthood when LS members were in their 20s, 30s and 40s. This would have been impossible using a dataset with shorter follow-up. The use of the large LS dataset also allowed us to model non-parental care by ethnicity, something impossible with smaller sample sizes. Using longitudinally linked census data reduced loss to follow-up, and the availability of covariate data improved the precision of, and reduced potential confounding in, our results.

We previously noted some limitations of earlier studies, namely i) a lack of a comparator group in parental care; ii) use of retrospective data; iii) a short follow-up into adulthood; iv) small sample size; and a non-UK location of the study. We have addressed all these limitations in this work. Random allocation to differing care types is not, of course, possible on ethical grounds, so causal interpretations of findings in this area must inevitably be approached with caution. Our decision to report average marginal effects is considered to get closer to a causal understanding from nonexperimental data than is usually possible. Indeed, it would be hard to understand how one could manipulate non-parental care in a randomised controlled study. But the logic of average marginal effects is similar to a matching study [50], since we estimate the associations for each individual twice - once assuming them in non-parental care and again assuming them in parental care with all their other characteristics the same. Since the only difference between these two estimates is whether they were in non-parental care or not, when we average over all individuals we can (cautiously) interpret non-parental care as the cause of the difference in the predicted outcomes, and the average marginal effect as a more realistic estimate of the magnitude of the difference [51]. 


\section{Implications and future research}

The main implication for policy for children in care is that, given the evidence on a White disadvantage rather than a Black or South Asian disadvantage, policies should be universally provided for all children in non-parental care and not targeted at specific ethnic groups.

Furthermore, policies to improve outcomes for ethnic minority children should be targeted to all minority children and not just those in non-parental care. The results also suggest that policies aimed at improving qualifications among those in non-parental care will have downstream benefits on employment and social mobility, especially for White and South Asian ethnic groups, which can be factored into any cost-benefit analysis of proposed interventions.

Moreover, there are several important implications for research. We urge researchers on life after non-parental care in childhood to include children who have not been in care in their sampling frames. This seems most critical for qualitative work since this methodology predominates in the field. Qualitative studies are needed to understand why South Asian care-leavers are more affected by their experiences in the long-term than Black care-leavers when compared with their same ethnicity peer group. This finding is especially puzzling since South Asian children are more likely to be in relative care and Black children in residential care $[52,53]$, yet outcomes by care-type are universally more positive for relative care than residential care [45].

Factors affecting placement type by ethnicity also needs to be featured more prominently in research. Even with larger samples than usual in this type of research, we still lacked the power to investigate ethnicity by placement type interactions. It is possible that register data in the Nordic countries could be employed to investigate this issue. We also need more fine-grained measures of ethnic group, again requiring larger samples for a thorough analysis. The socioeconomic environment of Indian families is more advantaged than that of Bangladeshi and Pakistani families in the UK, suggesting that relative care will not affect children in the same way across all South Asian families. Similarly, the migration histories of Black African and Black Caribbean people to the UK differ, affecting their social location which could also lead to differential outcomes after nonparental care. Finally, replication is recommended for confirmation of the reliability of our findings.

\section{Conclusion}

We started this study with the premise that ethnic minority children in non-parental care would suffer a double whammy from their experience, affecting their lives in the long-term. In one sense, we did find this in that ethnicity and non-parental care had additive associations with adult outcomes. However, we also uncovered the complexity of these relationships, with minority 
ethnicity moderating the non-parental care to adult outcomes relationship in both positive and negative ways. We challenge much of the previous work that made similar assumptions about ethnicity and non-parental care and relied on sampling children in non-parental care only for their evidence. 


\section{Acknowledgements}

The permission of the Office for National Statistics to use the Longitudinal Study is gratefully acknowledged, as is the help provided by staff of the Centre for Longitudinal Study Information \& User Support (CeLSIUS), especially Rachel Stuchbury and Alison Sizer. CeLSIUS is supported by the ESRC Census of Population Programme (Award Ref: ES/V003488/1). The authors alone are responsible for the interpretation of the data.

This work contains statistical data from ONS which is Crown Copyright. The use of the ONS statistical data in this work does not imply the endorsement of the ONS in relation to the interpretation or analysis of the statistical data. This work uses research datasets which may not exactly reproduce National Statistics aggregates.

The derivation of 1971 and 1981 NSSEC \& Goldthorpe classes is provided in Bukodi and Neuburger (2009) "Data Note. Job and occupational histories for the NSHD 1946 Birth Cohort" as part of the ESRC Gender Network Grant, Project 1 'Changing occupational careers of men and women', Reference: RES-225-25-2001. The code was kindly provided by Erzsebet Bukodi and adapted for use in the LS by Buscha and Sturgis as part of the ESRC grant 'Inter-cohort Trends in Intergenerational Mobility in England and Wales: income, status, and class (InTIME)', Reference: ES/K003259/1.

\section{Funding}

The project has been funded by the Nuffield Foundation (grant JUS/43052), but the views expressed are those of the authors and not necessarily the Foundation. Visit www.nuffieldfoundation.org We gratefully acknowledge their support, and that of the Economic and Social Research Council who fund the International Centre for Lifecourse Studies in Society and Health (grant ES/R008930/1). 


\section{References}

1. Bywaters, P., J. Kwhali, G. Brady, T. Sparks, and E. Bos, Out of Sight, Out of Mind: Ethnic Inequalities in Child Protection and Out-of-Home Care Intervention Rates. British Journal of Social Work, 2017. 47(7): p. 1884-1902 DOI: 10.1093/bjsw/bcw165.

2. Lu, Y.E., J. Landsverk, E. Ellis-Macleod, R. Newton, W. Ganger, and I. Johnson, Race, ethnicity, and case outcomes in child protective services. Children and Youth Services Review, 2004. 26(5): p. 447-461 DOI: 10.1016/j.childyouth.2004.02.002.

3. Mc Grath-Lone, L., L. Dearden, B. Nasim, K. Harron, and R. Gilbert, Changes in first entry to out-of-home care from 1992 to 2012 among children in England. Child Abuse \& Neglect, 2016. 51: p. 163-171 DOI: 10.1016/j.chiabu.2015.10.020.

4. Owen, C. and J. Statham, Disproportionality in child welfare: the prevalence of black and minority ethnic children within'looked after'and'children in need'populations and on child protection registers in England, in Research Report DCSF-RR124. 2009, Thomas Coram Research Unit, Institute of Education, University of London: London.

5. Villagrana, M., Racial/Ethnic Disparities in Mental Health Service Use for Older Foster Youth and Foster Care Alumni. Child and Adolescent Social Work Journal, 2017. 34(5): p. 419-429 DOI: $10.1007 / s 10560-016-0479-8$.

6. Wijedasa, D., The Prevalence and Characteristics of Children Growing Up with Relatives in the UK. 2015: Hadley Centre for Adoption and Foster Care Studies, University of Bristol ....

7. Hunter, K., Institutionalised Criminalisation: Black and Minority Ethnic Children and Looked After Children in the Youth Justice System in England and Wales. 2019, University of Liverpool.

8. Chand, A., Every child matters? A critical review of child welfare reforms in the context of minority ethnic children and families. Child Abuse Review: Journal of the British Association for the Study and Prevention of Child Abuse and Neglect, 2008. 17(1): p. 6-22.

9. Bywaters, P., J. Scourfield, C. Webb, K. Morris, B. Featherstone, G. Brady, ... T. Sparks, Paradoxical evidence on ethnic inequities in child welfare: Towards a research agenda. Children and Youth Services Review, 2019. 96(C): p. 145-154.

10. Bywaters, P., G. Brady, T. Sparks, E. Bos, L. Bunting, B. Daniel, . . . J. Scourfield, Exploring inequities in child welfare and child protection services: Explaining the inverse intervention law'. Children and Youth Services Review, 2015. 57: p. 98-105. 
11. Elliott, M. and J. Scourfield, Identifying and understanding inequalities in child welfare intervention rates. 2017.

12. Akister, J., M. Owens, and I.M. Goodyer, Leaving care and mental health: outcomes for children in out-of-home care during the transition to adulthood. Health Research Policy and Systems, 2010. 8(1): p. 10.

13. Botchway, S.K., M.A. Quigley, and R. Gray, Pregnancy-associated outcomes in women who spent some of their childhood looked after by local authorities: findings from the UK Millennium Cohort Study. BMJ open, 2014. 4(12): p. e005468.

14. Buehler, C., J.G. Orme, J. Post, and D.A. Patterson, The long-term correlates of family foster care. Children and Youth Services Review, 2000. 22(8): p. 595-625.

15. Cashmore, J. and M. Paxman, Wards leaving care: Follow up five years on. Children Australia, 2006. 31(03): p. 18-25.

16. Cheung, S.Y. and A. Buchanan, Malaise scores in adulthood of children and young people who have been in care. Journal of Child Psychology and Psychiatry, 1997. 38(5): p. 575-580.

17. Craine, N., C. Midgley, L. Zou, H. Evans, R. Whitaker, and M. Lyons, Elevated teenage conception risk amongst looked after children; a national audit. Public Health, 2014. 128(7): p. 668-670 DOI: 10.1016/j.puhe.2014.05.008.

18. Dregan, A. and M. Gulliford, Foster care, residential care and public care placement patterns are associated with adult life trajectories: population-based cohort study. Social psychiatry and psychiatric epidemiology, 2012. 47(9): p. 1517-1526.

19. Meltzer, H., D. Guinea-Martin, B. Millard, and L. Blackwell, A thirty-year prospective study of children in residential care in the 1970s. Scottish Journal of Residential Child Care, 2008. 7(1).

20. Murray, E.T., R. Lacey, B. Maughan, and A. Sacker, Non-parental care in childhood and health up to 30 years later: ONS Longitudinal Study 1971-2011. European Journal of Public Health, 2020.

21. Murray, E.T., R. Lacey, B. Maughan, and A. Sacker, Association of childhood out-of-home care status with all-cause mortality up to 42-years later: Office of National Statistics Longitudinal Study. BMC Public Health, 2020. 20: p. 1-10.

22. Viner, R.M. and B. Taylor, Adult health and social outcomes of children who have been in public care: population-based study. Pediatrics, 2005. 115(4): p. 894-899. 
23. Zlotnick, C., T.W. Tam, and L.A. Soman, Life course outcomes on mental and physical health: the impact of foster care on adulthood. American Journal of Public Health, 2012. 102(3): p. 534-540.

24. Barn, R., L. Andrew, and N. Mantovani, Life after care: The experiences of young people from different ethnic groups. 2005: Joseph Rowntree Foundation.

25. Combs, K.M., S. Begun, D.J. Rinehart, and H. Taussig, Pregnancy and Childbearing Among Young Adults Who Experienced Foster Care. Child Maltreatment, 2018. 23(2): p. 166-174 DOI: $10.1177 / 1077559517733816$.

26. Dworsky, A., C.R. White, K. O'Brien, P. Pecora, M. Courtney, R. Kessler, . . I. Hwang, Racial and ethnic differences in the outcomes of former foster youth. Children and Youth Services Review, 2010. 32(6): p. 902-912 DOI: 10.1016/j.childyouth.2010.03.001.

27. Garcia, A.R., P.J. Pecora, T. Harachi, and E. Aisenberg, Institutional Predictors of Developmental Outcomes Among Racially Diverse Foster Care Alumni. American Journal of Orthopsychiatry, 2012. 82(4): p. 573-584 DOI: 10.1111/j.1939-0025.2012.01181.x.

28. Harris, M.S., L.J. Jackson, K. O'Brien, and P. Pecora, Ethnic group comparisons in mental health outcomes of adult alumni of foster care. Children and Youth Services Review, 2010. 32(2): p. 171-177 DOI: 10.1016/j.childyouth.2009.08.010.

29. Prince, D.M., S. Vidal, N. Okpych, and C.M. Connell, Effects of individual risk and state housing factors on adverse outcomes in a national sample of youth transitioning out of foster care. Journal of Adolescence, 2019. 74: p. 33-44 DOI: 10.1016/j.adolescence.2019.05.004.

30. Tessier, N.G., A. O'Higgins, and R.J. Flynn, Neglect, educational success, and young people in out-of-home care: Cross-sectional and longitudinal analyses. Child Abuse \& Neglect, 2018. 75: p. 115-129 DOI: 10.1016/j.chiabu.2017.06.005.

31. Watt, T. and S. Kim, Race/ethnicity and foster youth outcomes: An examination of disproportionality using the national youth in transition database. Children and Youth Services Review, 2019. 102: p. 251-258 DOI: 10.1016/j.childyouth.2019.05.017.

32. Jivraj, S. and L. Simpson, Ethnic identity and inequalities in Britain: The dynamics of diversity. 2015: Policy Press.

33. Platt, L., Understanding inequalities: Stratification and difference. 2019: John Wiley \& Sons.

34. Hills, J., An anatomy of economic inequality in the UK-report of the national equality panel. LSE STICERD Research Paper No. CASEREPORT60, 2010. 
35. Shiner, M. and T. Modood, Help or Hindrance? Higher Education and the Route to Ethnic Equality. British Journal of Sociology of Education, 2002. 23(2): p. 209-232 DOI: 10.1080/01425690220137729.

36. Barnard, H. and C. Turner, Poverty and ethnicity: A review of evidence. York: JRF, 2011.

37. Nazroo, J.Y., The Structuring of Ethnic Inequalities in Health: Economic Position, Racial Discrimination, and Racism. American Journal of Public Health, 2003. 93(2): p. 277-284 DOI: 10.2105/ajph.93.2.277.

38. Villegas, S. and P.J. Pecora, Mental health outcomes for adults in family foster care as children: An analysis by ethnicity. Children and Youth Services Review, 2012. 34(8): p. 14481458 DOI: 10.1016/j.childyouth.2012.03.023.

39. Villegas, S., J.A. Rosenthal, K. O'Brien, and P. Pecora, Health outcomes for adults in family foster care as children: An analysis by ethnicity. Children and Youth Services Review, 2011. 33(1): p. 110-117 DOI: 10.1016/j.childyouth.2010.08.020.

40. Mantovani, N. and H. Thomas, Choosing motherhood: The complexities of pregnancy decision-making among young black women 'looked after' by the State. Midwifery, 2014. 30(3): p. E72-E78 DOI: 10.1016/j.midw.2013.10.015.

41. Yi, Y.M. and C. Wildeman, Can Foster Care Interventions Diminish Justice System Inequality? Future of Children, 2018. 28(1): p. 37-58 DOI: 10.1353/foc.2018.0002.

42. Crenshaw, K., Demarginalizing the intersection of race and sex: A black feminist critique of antidiscrimination doctrine, feminist theory and antiracist politics. u. Chi. Legal f., 1989: p. 139.

43. Office for National Statistics, Standard Occupational Classification 2010. 2010, Basingstoke, UK: Palgrave Macmillan.

44. Stata Press, Structural equation modeling reference manual. Release 16. 2019, College Station, Texas: StataCorp LLC.

45. Sacker, A., R.E. Lacey, B. Maughan, and E.T. Murray Out-of-home care in childhood and socioeconomic functioning in adulthood: ONS Longitudinal Study 1971-2011. SocArXiv, 2021. DOI: https://doi.org/10.31235/osf.io/f6b5x.

46. Holm, S., A simple sequentially rejective multiple test procedure. Scandinavian journal of statistics, 1979: p. 65-70. 
47. Osterberg, T., B. Gustafsson, and B. Vinnerljung, Children in Out-of-Home Care and Adult Labor-Market Attachment: A Swedish National Register Study. Journal of Public Child Welfare, 2016. 10(4): p. 414-433 DOI: 10.1080/15548732.2016.1209148.

48. Fernandez, E., J.S. Lee, and P. McNamara, 'Uprooted from Everything that Attaches You': Long-Term Outcomes of Former Child Migrants in Care in the Twentieth Century in Australia. British Journal of Social Work, 2019. 49(2): p. 523-545 DOI: 10.1093/bjsw/bcy070.

49. Cameron, C., K. Hollingworth, I. Schoon, E. van Santen, W. Schroer, T. Ristikari, ... E. Pekkarinen, Care leavers in early adulthood: How do they fare in Britain, Finland and Germany? Children and Youth Services Review, 2018. 87: p. 163-172 DOI: 10.1016/j.childyouth.2018.02.031.

50. Williams, R., Using the margins command to estimate and interpret adjusted predictions and marginal effects. The Stata Journal, 2012. 12(2): p. 308-331.

51. Bartus, T., Estimation of marginal effects using margeff. The Stata Journal, 2005. 5(3): p. 309-329.

52. Ofsted Children looked after placements by English local authorities as at 31 March 2014. 2015.

53. Nandy, S., J. Selwyn, E. Farmer, and P. Vaisey, Spotlight on kinship care. Bristol: University of Bristol, 2011. 304(10). 
Table 1. Maximum number (\%) of observations with data at age 20-29, 30-39, and 40-49 follow-ups, ONS Longitudinal Study. ${ }^{1}$

\begin{tabular}{|l|c|c|c|c|}
\hline & Age 20-29 & Age 30-39 & Age 40-49 & Total \\
\hline Parental care & & & & \\
\hline White & $291,099(94.7)$ & $206,594(95.7)$ & $137,776(96.5)$ & $635,469(95.4)$ \\
\hline Black & $5,448(1.8)$ & $3,124(1.5)$ & $2,354(1.7)$ & $10,926(1.6)$ \\
\hline South Asian & $10,869(3.5)$ & $6,111(2.8)$ & $2,691(1.9)$ & $19,671(3.0)$ \\
\hline Total & 307,416 & 215,829 & 142,821 & 666,066 \\
\hline Non-parental care & & & & $1,289(85.5)$ \\
\hline White & $2,521(85.9)$ & $1,833(85.7)$ & $108(7.2)$ & $438(6.7)$ \\
\hline Black & $192(6.5)$ & $138(6.5)$ & $111(7.4)$ & $501(7.6)$ \\
\hline South Asian & $221(7.5)$ & $169(7.9)$ & 1,508 & 6,582 \\
\hline Total & 2,934 & 2,140 & 144,329 & 672,648 \\
\hline Grand total & 310,350 & 217,969 & & \\
\hline
\end{tabular}

${ }^{1}$ Number varies for different adult outcomes 
Table 2. Childhood sample characteristics ${ }^{1}$ by care type and follow-up age group: ONS Longitudinal Study

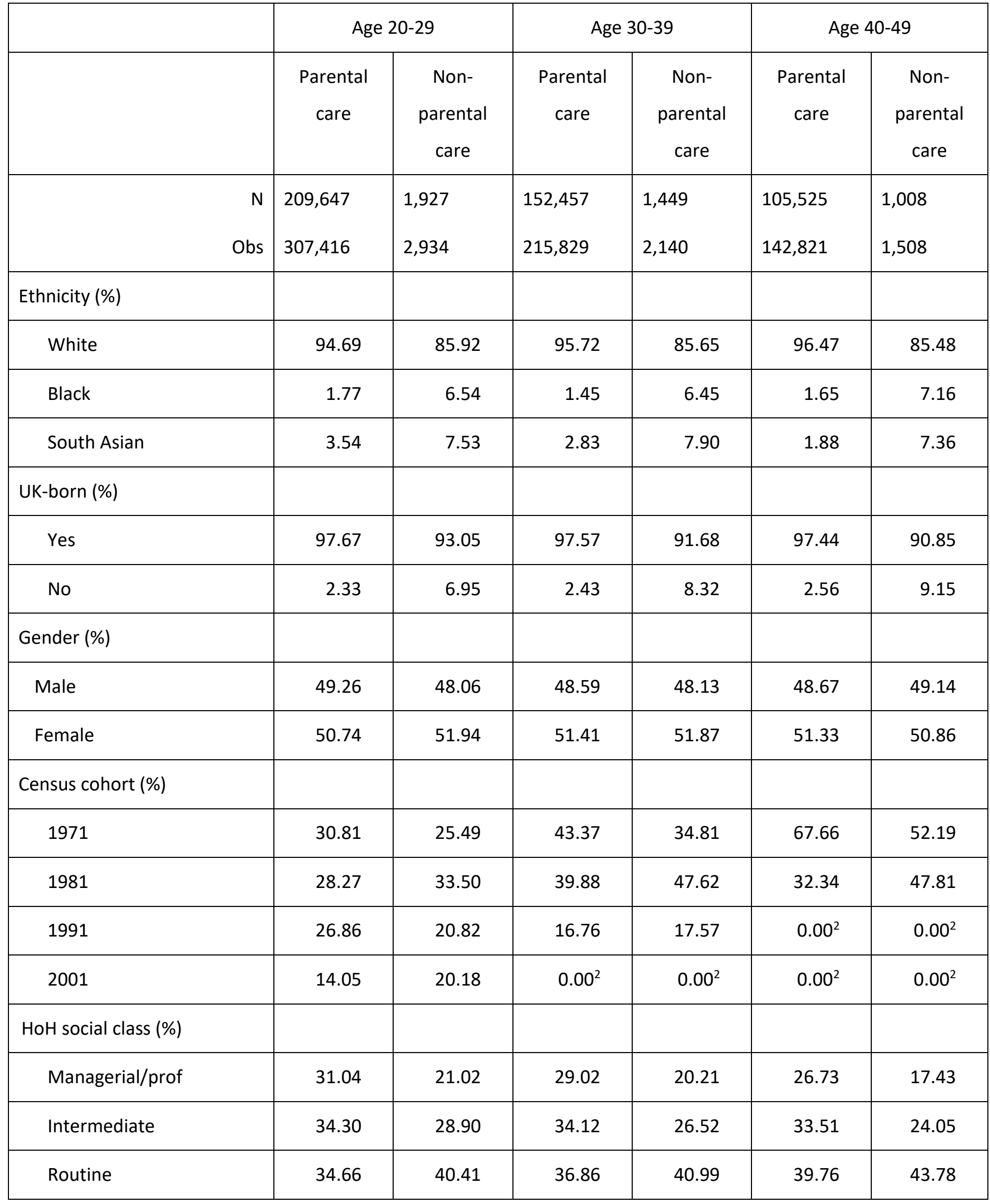




\begin{tabular}{|c|c|c|c|c|c|c|}
\hline & \multicolumn{2}{|c|}{ Age $20-29$} & \multicolumn{2}{|c|}{ Age 30-39 } & \multicolumn{2}{|c|}{ Age $40-49$} \\
\hline & $\begin{array}{c}\text { Parental } \\
\text { care }\end{array}$ & $\begin{array}{c}\text { Non- } \\
\text { parental } \\
\text { care }\end{array}$ & $\begin{array}{c}\text { Parental } \\
\text { care }\end{array}$ & $\begin{array}{c}\text { Non- } \\
\text { parental } \\
\text { care }\end{array}$ & $\begin{array}{c}\text { Parental } \\
\text { care }\end{array}$ & $\begin{array}{c}\text { Non- } \\
\text { parental } \\
\text { care }\end{array}$ \\
\hline N/A & $0.00^{2}$ & 9.68 & $0.00^{2}$ & 12.29 & $0.00^{2}$ & 14.73 \\
\hline \multicolumn{7}{|l|}{ HoH qualifications (\%) } \\
\hline$\geq 18$-year qual & 16.88 & 10.77 & 13.61 & 8.13 & 11.18 & 5.84 \\
\hline$<18$-year qual & 83.12 & 79.69 & 86.39 & 79.77 & 88.82 & 79.71 \\
\hline $\mathrm{N} / \mathrm{A}$ & $0.00^{2}$ & 9.54 & $0.00^{2}$ & 12.10 & $0.00^{2}$ & 14.46 \\
\hline \multicolumn{7}{|l|}{ HoH employment (\%) } \\
\hline In work & 91.10 & 70.28 & 93.30 & 71.64 & 94.85 & 71.75 \\
\hline Unemployed & 4.68 & 6.13 & 4.88 & 6.96 & 4.03 & 5.97 \\
\hline OLF & 4.22 & 14.04 & 1.83 & 9.30 & 1.12 & 7.82 \\
\hline N/A & $0.00^{2}$ & 9.54 & $0.00^{2}$ & 12.10 & $0.00^{2}$ & 14.46 \\
\hline \multicolumn{7}{|l|}{ HoH marital status (\%) } \\
\hline Married & 91.08 & 63.33 & 94.52 & 64.67 & 95.62 & 65.12 \\
\hline Divorced/widowed & 6.17 & 15.71 & 4.63 & 12.71 & 3.86 & 11.21 \\
\hline Single & 2.75 & 11.42 & 0.85 & 10.51 & 0.52 & 9.22 \\
\hline $\mathrm{N} / \mathrm{A}$ & $0.00^{2}$ & 9.54 & $0.00^{2}$ & 12.10 & $0.00^{2}$ & 14.46 \\
\hline Childhood age (mean) & 9.45 & 11.43 & 9.72 & 11.51 & 10.13 & 12.29 \\
\hline
\end{tabular}

${ }^{1}$ Across all observations

${ }^{2}$ Cell count zero by design.

Obs: observations; $\mathrm{HOH}$ : head of household; OLF: out of the labour force (e.g. homemaker/carer; permanently sick, other); Parent: parental care; Care: non-parental care 
Table 3. Adult outcomes after parental care or non-parental care by ethnicity, averaged over follow-up age groups ${ }^{1}$ : ONS Longitudinal Study.

\begin{tabular}{|c|c|c|c|c|c|c|}
\hline & \multicolumn{3}{|c|}{ Parental care } & \multicolumn{3}{|c|}{ Non-parental care } \\
\hline & White & Black & South Asian & White & Black & South Asian \\
\hline \multicolumn{7}{|l|}{ Self-rated health (\%) } \\
\hline Good & 84.28 & 80.78 & 85.44 & 72.11 & 72.41 & 72.21 \\
\hline Poor & 15.72 & 19.22 & 14.56 & 27.89 & 27.59 & 27.79 \\
\hline \multicolumn{7}{|c|}{ Limiting long-term illness (\%) } \\
\hline No & 92.61 & 91.18 & 92.85 & 84.02 & 86.68 & 89.69 \\
\hline Yes & 7.39 & 8.82 & 7.15 & 15.98 & 13.32 & 10.31 \\
\hline \multicolumn{7}{|c|}{ Highest qualification (\%) } \\
\hline$\geq 18$ years quals & 32.40 & 35.04 & 48.14 & 19.99 & 33.18 & 26.75 \\
\hline$<18$ years quals & 67.60 & 64.96 & 51.86 & 80.01 & 66.82 & 73.25 \\
\hline \multicolumn{7}{|c|}{$\begin{array}{l}\text { Long-term non-employed } \\
\text { (\%) }\end{array}$} \\
\hline No & 96.74 & 96.12 & 96.02 & 93.22 & 93.46 & 94.46 \\
\hline Yes & 3.26 & 3.88 & 3.98 & 6.78 & 6.54 & 5.54 \\
\hline \multicolumn{7}{|c|}{$\begin{array}{l}\text { Current employment status } \\
\text { (\%) }\end{array}$} \\
\hline In work & 77.18 & 65.91 & 63.39 & 61.92 & 65.01 & 63.27 \\
\hline Unemployed & 6.16 & 12.91 & 9.47 & 11.06 & 9.71 & 13.17 \\
\hline Education & 3.57 & 4.70 & 6.93 & 5.94 & 6.32 & 4.79 \\
\hline Other & 13.10 & 16.47 & 20.21 & 21.08 & 18.96 & 18.76 \\
\hline \multicolumn{7}{|l|}{ Social class (\%) } \\
\hline Managerial/prof & 31.70 & 27.46 & 33.98 & 19.54 & 26.71 & 22.04 \\
\hline Intermediate & 28.79 & 27.30 & 23.26 & 24.53 & 23.06 & 31.26 \\
\hline Routine & 29.94 & 26.69 & 20.32 & 39.19 & 31.74 & 24.85 \\
\hline
\end{tabular}




\begin{tabular}{|c|c|c|c|c|c|c|}
\hline & \multicolumn{3}{|c|}{ Parental care } & \multicolumn{3}{|c|}{ Non-parental care } \\
\hline & White & Black & South Asian & White & Black & South Asian \\
\hline $\mathrm{N} / \mathrm{K}$ & 9.57 & 18.55 & 22.44 & 16.73 & 18.49 & 21.84 \\
\hline \multicolumn{7}{|l|}{ Housing tenure (\%) } \\
\hline Owner-occupier & 69.20 & 53.18 & 78.64 & 49.85 & 36.90 & $>76.25$ \\
\hline Renting & 28.09 & 44.03 & 18.25 & 45.42 & 56.72 & $>21.76$ \\
\hline Other & 2.71 & 2.79 & 3.10 & 4.73 & 6.38 & $<2.00$ \\
\hline \multicolumn{7}{|l|}{ Overcrowding (\%) } \\
\hline No & 97.70 & 94.50 & 87.86 & 96.22 & 94.96 & 76.77 \\
\hline Yes & 2.30 & 5.50 & 12.14 & 3.78 & 5.04 & 23.23 \\
\hline \multicolumn{7}{|l|}{ Living alone (\%) } \\
\hline No & 97.55 & 96.18 & 97.63 & 95.18 & 92.10 & $>98.02$ \\
\hline Yes & 2.45 & 3.82 & 2.27 & 4.82 & 7.90 & $<1.98$ \\
\hline \multicolumn{7}{|l|}{ Marital status (\%) } \\
\hline Married & 41.52 & 21.28 & 45.09 & 38.97 & 24.15 & 65.07 \\
\hline Divorced/widowed & 6.12 & 3.73 & 3.29 & 8.96 & 5.42 & 3.39 \\
\hline Single & 52.36 & 74.99 & 51.62 & 52.07 & 70.43 & 31.54 \\
\hline $\begin{array}{l}\text { Mean number children } \\
\text { (women only) }\end{array}$ & 1.02 & 0.92 & 0.86 & 0.71 & 0.39 & 0.44 \\
\hline $\begin{array}{l}\text { Mean age at } 1^{\text {st }} \text { child } \\
\text { (parous women only) }\end{array}$ & 25.33 & 24.10 & 25.43 & 22.91 & 21.98 & 24.75 \\
\hline
\end{tabular}

${ }^{1}$ Cell counts $<10$ have been suppressed. Percentages are based on a count of 10 when cells are supressed 
Table 4. Average marginal effects ${ }^{1}$ for age $20-29$ year outcomes regressed on ethnicity and non-parental care groupings: ONS Longitudinal Study

\begin{tabular}{|c|c|c|c|c|}
\hline & White & Black & South Asian & $P^{2}$ \\
\hline Self-rated health & $0.08(0.06,0.10)$ & $0.06(-0.02,0.15)$ & $0.01(-0.05,0.06)$ & 0.15 \\
\hline Limiting long-term illness & $0.04(0.03,0.06)$ & $0.03(-0.01,0.07)$ & $0.02(-0.01,0.06)$ & 0.61 \\
\hline$<18$-year qualifications & $0.10(0.08,0.11)$ & $0.01(-0.05,0.08)$ & $0.08(0.02,0.14)$ & 0.012 \\
\hline Employment status & & & & $<0.00005$ \\
\hline Employed & $-0.12(-0.14,-0.10)$ & $0.04(-0.04,0.11)$ & $0.01(-0.06,0.07)$ & \\
\hline Unemployed & $0.05(0.03,0.06)$ & $-0.05(-0.10,-0.01)$ & $0.05(0.00,0.10)$ & \\
\hline In education & $0.00(-0.01,0.01)$ & $-0.01(-0.05,0.03)$ & $-0.06(-0.09,-0.02)$ & \\
\hline OLF & $0.07(0.05,0.08)$ & $0.02(-0.03,0.08)$ & $0.00(-0.05,0.05)$ & \\
\hline Long-term nonemployed & $0.01(0.01,0.02)$ & $0.00(-0.03,0.02)$ & $-0.02(-0.05,0.01)$ & 0.034 \\
\hline Social class ${ }^{3}$ & & & & 0.0080 \\
\hline Managerial/professional & $-0.08(-0.09,-0.06)$ & $0.01(-0.05,0.08)$ & $-0.08(-0.13,-0.02)$ & \\
\hline Intermediate/technical & $-0.04(-0.06,-0.02)$ & $-0.01(-0.08,0.06)$ & $-0.01(-0.07,0.04)$ & \\
\hline Routine occupations & $0.07(0.05,0.09)$ & $0.05(-0.02,0.12)$ & $0.05(0.00,0.11)$ & \\
\hline Not known & $0.05(0.03,0.07)$ & $-0.06(-0.11,0.00)$ & $0.04(-0.03,0.10)$ & \\
\hline Housing tenure & & & & 0.0055 \\
\hline Owner occupier & $-0.13(-0.15,-0.10)$ & $-0.19(-0.27,-0.11)$ & $-0.01(-0.06,0.04)$ & \\
\hline Renting & $0.11(0.09,0.13)$ & $0.15(0.07,0.23)$ & $0.03(-0.02,0.08)$ & \\
\hline Other & $0.01(0.00,0.02)$ & $0.04(0.00,0.08)$ & $-0.02(-0.04,0.00)$ & \\
\hline Overcrowding & $0.01(0.00,0.02)$ & $-0.01(-0.04,0.03)$ & $0.06(0.01,0.11)$ & 0.29 \\
\hline Lives alone & $0.02(0.01,0.04)$ & $0.04(0.00,0.09)$ & $-0.02(-0.04,0.00)$ & 0.038 \\
\hline Marital status & & & & 0.041 \\
\hline Currently married & $0.03(0.01,0.04)$ & $0.02(-0.03,0.07)$ & $0.12(0.06,0.18)$ & \\
\hline Previously married & $0.01(0.00,0.02)$ & $0.01(0.00,0.03)$ & $0.00(-0.02,0.01)$ & \\
\hline Single & $-0.04(-0.05,-0.02)$ & $-0.03(-0.08,0.02)$ & $-0.12(-0.18,-0.06)$ & \\
\hline Number of children ${ }^{3}$ & $0.00(-0.04,0.05)$ & $-0.12(-0.25,0.01)$ & $-0.08(-0.23,0.06)$ & 0.19 \\
\hline
\end{tabular}




\begin{tabular}{|c|c|c|c|c|}
\hline & White & Black & South Asian & $P^{2}$ \\
\hline Age at first child ${ }^{4}$ & $-0.96(-1.23,-0.69)$ & $-0.21(-1.56,1.14)$ & $-0.05(-1.33,1.23)$ & 0.24 \\
\hline
\end{tabular}

${ }^{1}$ Average marginal effect $=$ average difference between predicted effect if in non-parental care and predicted effect if in parental care, leaving all other covariates as observed

${ }^{2}$ Wald tests of significance of care group by ethnicity interaction

${ }^{3}$ Women only

${ }^{4}$ Parous women only 
Table 5. Average marginal effects ${ }^{1}$ for age $30-39$ year outcomes regressed on ethnicity and non-parental care groupings: ONS Longitudinal Study

\begin{tabular}{|c|c|c|c|c|}
\hline & White & Black & South Asian & $P^{2}$ \\
\hline Self-rated health & $0.10(0.08,0.13)$ & $0.06(-0.03,0.15)$ & $0.09(0.01,0.17)$ & 0.55 \\
\hline Limiting long-term illness & $0.05(0.04,0.07)$ & $0.02(-0.03,0.07)$ & $-0.01(-0.04,0.03)$ & 0.043 \\
\hline$<18$-year qualifications & $0.10(0.07,0.12)$ & $-0.02(-0.12,0.07)$ & $0.15(0.08,0.22)$ & 0.0089 \\
\hline Employment status & & & & 0.043 \\
\hline Employed & $-0.09(-0.11,-0.07)$ & $0.04(-0.03,0.11)$ & $-0.06(-0.13,0.01)$ & \\
\hline Unemployed & $0.02(0.01,0.03)$ & $-0.04(-0.07,0.00)$ & $0.02(-0.01,0.06)$ & \\
\hline In education & $0.03(0.02,0.04)$ & $0.02(-0.01,0.06)$ & $0.02(-0.01,0.05)$ & \\
\hline OLF & $0.04(0.02,0.06)$ & $-0.02(-0.08,0.03)$ & $0.01(-0.05,0.08)$ & \\
\hline Long-term nonemployed & $0.02(0.01,0.04)$ & $0.02(-0.01,0.06)$ & $0.00(-0.03,0.04)$ & 0.53 \\
\hline Social class ${ }^{3}$ & & & & 0.0063 \\
\hline Managerial/professional & $-0.12(-0.14,-0.09)$ & $0.01(-0.08,0.11)$ & $-0.15(-0.22,-0.07)$ & \\
\hline Intermediate/technical & $0.00(-0.03,0.02)$ & $-0.08(-0.15,0.00)$ & $0.07(0.00,0.14)$ & \\
\hline Routine occupations & $0.07(0.05,0.10)$ & $0.06(-0.02,0.15)$ & $0.04(-0.02,0.09)$ & \\
\hline Not known & $0.05(0.03,0.06)$ & $0.00(-0.05,0.04)$ & $0.04(-0.01,0.09)$ & \\
\hline Housing tenure & & & & 0.039 \\
\hline Owner occupier & $-0.15(-0.17,-0.12)$ & $-0.11(-0.20,-0.01)$ & $-0.03(-0.08,0.02)$ & \\
\hline Renting & $0.13(0.10,0.15)$ & $0.06(-0.03,0.15)$ & $0.04(-0.01,0.09)$ & \\
\hline Other & $0.02(0.01,0.03)$ & $0.05(0.00,0.09)$ & $-0.01(-0.02,0.01)$ & \\
\hline Overcrowding & $0.02(0.01,0.02)$ & $0.00(-0.03,0.03)$ & $0.04(0.00,0.08)$ & 0.54 \\
\hline Lives alone & $0.02(0.01,0.03)$ & $0.04(-0.01,0.09)$ & $-0.01(-0.01,-0.01)$ & $<0.00005$ \\
\hline Marital status & & & & 0.089 \\
\hline Currently married & $0.01(-0.04,0.00)$ & $0.05(0.13,0.00)$ & $0.03(0.08,0.00)$ & \\
\hline Previously married & $0.01(0.04,0.00)$ & $0.02(0.05,0.00)$ & $0.02(0.05,0.00)$ & \\
\hline Single & $0.01(0.07,0.00)$ & $0.05(0.04,0.00)$ & $0.03(0.03,0.00)$ & \\
\hline Number of children ${ }^{3}$ & $-0.50(-0.59,-0.41)$ & $-0.64(-0.90,-0.38)$ & $-0.71(-1.00,-0.42)$ & 0.20 \\
\hline
\end{tabular}




\begin{tabular}{|l|c|c|c|c|}
\hline & White & Black & South Asian & $P^{2}$ \\
\hline Age at first child ${ }^{4}$ & $-1.62(-2.13,-1.11)$ & $-1.19(-3.35,0.98)$ & $-0.43(-2.15,1.30)$ & 0.41 \\
\hline
\end{tabular}

\footnotetext{
${ }^{1}$ Average marginal effect $=$ average difference between predicted effect if in non-parental care and predicted effect if in parental care, leaving all other covariates as observed

${ }^{2}$ Wald tests of significance of care group by ethnicity interaction

${ }^{3}$ Women only

${ }^{4}$ Parous women only
} 
Table 6. Average marginal effects ${ }^{1}$ for age 40-49 year outcomes regressed on ethnicity and non-parental care groupings: ONS Longitudinal Study

\begin{tabular}{|c|c|c|c|c|}
\hline & White & Black & South Asian & $P^{2}$ \\
\hline Self-rated health & $0.08(0.06,0.11)$ & $0.06(-0.04,0.15)$ & $0.14(0.06,0.23)$ & 0.30 \\
\hline Limiting long-term illness & $0.08(0.06,0.11)$ & $-0.01(-0.07,0.06)$ & $0.04(-0.03,0.10)$ & 0.030 \\
\hline$<18$-year qualifications & $0.05(0.02,0.08)$ & $-0.05(-0.15,0.06)$ & $0.20(0.11,0.28)$ & 0.0021 \\
\hline Employment status & & & & 0.54 \\
\hline Employed & $-0.10(-0.12,-0.07)$ & $-0.01(-0.09,0.07)$ & $-0.09(-0.17,0.00)$ & \\
\hline Unemployed & $0.02(0.00,0.03)$ & $-0.01(-0.05,0.03)$ & $0.02(-0.02,0.06)$ & \\
\hline In education & $0.04(0.02,0.06)$ & $0.03(-0.02,0.08)$ & $0.02(-0.02,0.07)$ & \\
\hline OLF & $0.04(0.02,0.06)$ & $-0.01(-0.06,0.04)$ & $0.04(-0.03,0.12)$ & \\
\hline Long-term nonemployed & $0.03(0.01,0.04)$ & $0.02(-0.03,0.07)$ & $0.06(0.00,0.12)$ & 0.56 \\
\hline Social class ${ }^{3}$ & & & & 0.0023 \\
\hline Managerial/professional & $-0.06(-0.09,-0.03)$ & $0.00(-0.11,0.10)$ & $-0.16(-0.25,-0.07)$ & \\
\hline Intermediate/technical & $-0.02(-0.05,0.01)$ & $0.01(-0.09,0.11)$ & $0.16(0.07,0.26)$ & \\
\hline Routine occupations & $0.05(0.02,0.08)$ & $-0.01(-0.09,0.07)$ & $-0.02(-0.08,0.05)$ & \\
\hline Not known & $0.04(0.02,0.05)$ & $0.00(-0.04,0.04)$ & $0.01(-0.03,0.06)$ & \\
\hline Housing tenure & & & & 0.19 \\
\hline Owner occupier & $-0.13(-0.16,-0.10)$ & $-0.05(-0.15,0.04)$ & $-0.05(-0.12,0.03)$ & \\
\hline Renting & $0.12(0.09,0.15)$ & $0.06(-0.04,0.16)$ & $0.05(-0.02,0.12)$ & \\
\hline Other & $0.01(0.00,0.02)$ & $-0.01(-0.03,0.02)$ & $-0.01(-0.02,0.01)$ & \\
\hline Overcrowding & $0.00(-0.01,0.01)$ & $-0.02(-0.04,0.00)$ & $0.08(0.02,0.13)$ & 0.0059 \\
\hline Lives alone & $0.01(0.00,0.02)$ & $0.00(-0.01,0.02)$ & $0.00(0.00,0.00)$ & $<0.00005$ \\
\hline Marital status & & & & 0.032 \\
\hline Currently married & $-0.07(-0.10,-0.04)$ & $-0.01(-0.12,0.10)$ & $0.09(0.03,0.16)$ & \\
\hline Previously married & $0.04(0.02,0.07)$ & $0.01(-0.05,0.07)$ & $-0.05(-0.09,0.00)$ & \\
\hline Single & $0.02(0.00,0.05)$ & $0.00(-0.10,0.11)$ & $-0.05(-0.10,0.00)$ & \\
\hline Number of children ${ }^{3}$ & $-0.77(-0.88,-0.66)$ & $-0.95(-1.34,-0.57)$ & $-1.34(-1.75,-0.94)$ & 0.13 \\
\hline
\end{tabular}




\begin{tabular}{|l|c|c|c|l|}
\hline & White & Black & South Asian & \multicolumn{1}{|c|}{$P^{2}$} \\
\hline Age at first child $^{4}$ & $-2.07(-2.75,-1.39)$ & $-2.99(-5.80,-0.19)$ & $-0.06(-3.20,3.08)$ & 0.37 \\
\hline
\end{tabular}

${ }^{1}$ Average marginal effect $=$ average difference between predicted effect if in non-parental care and predicted effect if in parental care, leaving all other covariates as observed

${ }^{2}$ Wald tests of significance of care group by ethnicity interaction

${ }^{3}$ Women only

${ }^{4}$ Parous women only 
Table S1. Childhood characteristics of the analysis sample compared with all available data, complete and incomplete childhood data, and $\geq 1$ follow-up age groups missing: ONS Longitudinal Study

\begin{tabular}{|c|c|c|c|c|c|c|c|c|c|c|}
\hline & \multicolumn{2}{|c|}{ Full data ${ }^{2,6}$} & \multicolumn{2}{|c|}{$\begin{array}{c}\text { Complete childhood } \\
\text { data }^{3}\end{array}$} & \multicolumn{2}{|c|}{$\begin{array}{c}\text { Incomplete childhood } \\
\text { data }^{4,6}\end{array}$} & \multicolumn{2}{|c|}{$\begin{array}{l}\text { Missing follow-up } \\
\text { data }^{5,6}\end{array}$} & \multicolumn{2}{|c|}{ Analysis sample $^{6}$} \\
\hline & Obs & $\%$ & Obs & $\%$ & Obs & $\%$ & Obs & $\%$ & Obs & $\%$ \\
\hline \multicolumn{11}{|l|}{ Ethnicity } \\
\hline White & 782,360 & 94.24 & 724,146 & 94.82 & 58,214 & 87.56 & 94,080 & 90.04 & 641,112 & 95.31 \\
\hline Black & 18,928 & 2.28 & 15,097 & 1.98 & 3,831 & 5.76 & 5,026 & 4.81 & 11,364 & 1.69 \\
\hline South Asian & 28,874 & 3.48 & 24,433 & 3.20 & 4,441 & 6.68 & 5,379 & 5.15 & 20,172 & 3.00 \\
\hline \multicolumn{11}{|l|}{ UK-born } \\
\hline Yes & 805,761 & 97.07 & 742,754 & 97.26 & 63,007 & 94.90 & 99,042 & 94.83 & 656,084 & 97.54 \\
\hline No & 24,308 & 2.93 & 20,922 & 2.74 & 3,386 & 5.10 & 5,401 & 5.17 & 16,564 & 2.46 \\
\hline \multicolumn{11}{|l|}{ Gender } \\
\hline Male & 417,435 & 50.28 & 384,495 & 50.35 & 32,940 & 49.54 & 63,774 & 61.04 & 328,993 & 48.91 \\
\hline Female & 412,727 & 49.72 & 379,181 & 49.65 & 33,546 & 50.46 & 40,711 & 38.96 & 343,655 & 51.09 \\
\hline \multicolumn{11}{|l|}{ HoH social class } \\
\hline Managerial/prof & 223,773 & 29.30 & 223,763 & 29.31 & 10 & 11.76 & 26,236 & 28.83 & 197,528 & 29.37 \\
\hline Intermediate & 258,617 & 33.87 & 258,602 & 33.87 & 15 & 17.65 & 29,927 & 32.89 & 228,679 & 34.00 \\
\hline Routine & 280,261 & 36.70 & 280,217 & 36.70 & 44 & 51.76 & 34,649 & 38.08 & 245,580 & 36.51 \\
\hline N/A & 955 & 0.13 & 939 & 0.12 & 16 & 18.82 & 186 & 0.20 & 762 & 0.11 \\
\hline
\end{tabular}




\begin{tabular}{|c|c|c|c|c|c|c|c|c|c|c|}
\hline & \multicolumn{2}{|c|}{ Full data ${ }^{2,6}$} & \multicolumn{2}{|c|}{$\begin{array}{c}\text { Complete childhood } \\
\text { data }^{3}\end{array}$} & \multicolumn{2}{|c|}{$\begin{array}{c}\text { Incomplete childhood } \\
\text { data } \\
\text { d,6 }\end{array}$} & \multicolumn{2}{|c|}{$\begin{array}{c}\text { Missing follow-up } \\
\text { data }^{5,6}\end{array}$} & \multicolumn{2}{|c|}{ Analysis sample ${ }^{6}$} \\
\hline & Obs & $\%$ & Obs & $\%$ & Obs & $\%$ & Obs & $\%$ & Obs & $\%$ \\
\hline \multicolumn{11}{|l|}{ HoH qualifications } \\
\hline$\geq 18$-year qual & 113,701 & 13.70 & 111,422 & 14.59 & 2,279 & 3.44 & 14,105 & 13.51 & 97,832 & 14.54 \\
\hline$<18$-year qual & 715,234 & 86.18 & 651,315 & 85.29 & 63,919 & 96.53 & 90,121 & 86.31 & 574,054 & 85.34 \\
\hline N/A & 955 & 0.12 & 939 & 0.12 & 16 & 0.02 & 186 & 0.18 & 762 & 0.11 \\
\hline \multicolumn{11}{|l|}{ HoH employment } \\
\hline In work & 708,835 & 85.41 & 699,882 & 91.65 & 8,953 & 13.52 & 79,493 & 76.14 & 621,549 & 92.40 \\
\hline Unemployed & 47,856 & 5.77 & 38,084 & 4.99 & 9,772 & 14.76 & 9,398 & 9.00 & 31,079 & 4.62 \\
\hline OLF & 72,230 & 8.70 & 24,771 & 3.24 & 47,459 & 71.69 & 15,327 & 14.68 & 19,258 & 2.86 \\
\hline N/A & 955 & 0.12 & 939 & 0.12 & 16 & 0.02 & 186 & 0.18 & 762 & 0.11 \\
\hline \multicolumn{11}{|l|}{$\mathrm{HoH}$ marital status } \\
\hline Married & 740,761 & 89.25 & 704,374 & 92.23 & 36,387 & 54.86 & 86,576 & 82.90 & 624,790 & 92.89 \\
\hline Divorced/widowed & 65,876 & 7.94 & 42,762 & 5.60 & 23,114 & 34.85 & 11,611 & 11.12 & 35,361 & 5.26 \\
\hline Single & 22,411 & 2.70 & 15,601 & 2.04 & 6,810 & 10.27 & 6,062 & 5.80 & 11,735 & 1.74 \\
\hline \multirow[t]{2}{*}{ N/A } & 955 & 0.12 & 939 & 0.12 & 16 & 0.02 & 186 & 0.18 & 762 & 0.11 \\
\hline & Mean & $95 \% \mathrm{Cl}$ & Mean & $95 \% \mathrm{Cl}$ & Mean & $95 \% \mathrm{Cl}$ & Mean & $95 \% \mathrm{Cl}$ & Mean & $95 \% \mathrm{Cl}$ \\
\hline Childhood age & 9.68 & $9.67,9.69$ & 9.67 & $9.65,9.68$ & 9.81 & $9.77,9.85$ & 9.38 & $9.35,9.41$ & 9.70 & $9.69,9.72$ \\
\hline
\end{tabular}

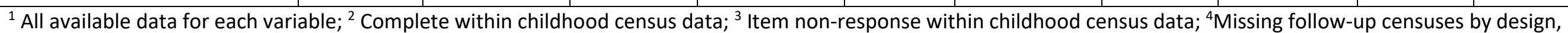
non-response or linkage problems; ${ }^{5}$ Analysis sample; ${ }^{6}$ Total counts for each variable can differ 
Table S2. Estimates (95\% confidence intervals) for social outcomes regressed on ethnicity by care interaction, age 20-29 follow-up: ONS Longitudinal Study

\begin{tabular}{|c|c|c|c|c|c|c|c|}
\hline & \multirow[t]{2}{*}{$\mathrm{RE}$} & \multicolumn{2}{|c|}{ White } & \multicolumn{2}{|c|}{ Black } & \multicolumn{2}{|c|}{ South Asian } \\
\hline & & Parental care & Non-parental care & Parental care & Non-parental care & Parental care & Non-parental care \\
\hline Self-rated health ${ }^{1}$ & OR & 1.00 (Reference) & $1.86(1.58,2.13)$ & $1.16(1.00,1.31)$ & $1.89(0.83,2.95)$ & $0.95(0.86,1.04)$ & $1.03(0.48,1.57)$ \\
\hline Limiting long-term illness $^{1}$ & OR & 1.00 (Reference) & $1.97(1.67,2.28)$ & $1.00(0.84,1.16)$ & $1.63(0.67,2.59)$ & $0.89(0.78,0.99)$ & $1.42(0.64,2.19)$ \\
\hline$<18$-year qualifications ${ }^{1}$ & OR & 1.00 (Reference) & $2.01(1.74,2.28)$ & $0.87(0.80,0.94)$ & $0.96(0.57,1.35)$ & $0.54(0.51,0.57)$ & $0.85(0.57,1.13)$ \\
\hline Employment status $^{3}$ & RRR & & & & & & \\
\hline \multicolumn{8}{|l|}{ Employed (Reference) } \\
\hline Unemployed & & 1.00 (Reference) & $1.82(1.59,2.06)$ & $2.03(1.84,2.23)$ & $1.28(0.67,1.89)$ & $1.62(1.49,1.75)$ & $2.28(1.40,3.16)$ \\
\hline In education & & 1.00 (Reference) & $1.27(0.98,1.55)$ & $1.64(1.40,1.89)$ & $1.37(0.40,2.34)$ & $3.33(3.03,3.63)$ & $1.64(0.61,2.67)$ \\
\hline OLF & & 1.00 (Reference) & $1.77(1.57,1.97)$ & $1.45(1.31,1.58)$ & $1.60(0.97,2.22)$ & $1.92(1.80,2.05)$ & $1.93(1.27,2.58)$ \\
\hline Long-term nonemployed $^{1}$ & OR & 1.00 (Reference) & $1.67(1.26,2.09)$ & $1.62(1.29,1.95)$ & $1.43(0.28,2.58)$ & $2.82(2.39,3.26)$ & $1.79(0.17,3.41)$ \\
\hline Social class ${ }^{3}$ & RRR & & & & & & \\
\hline \multicolumn{8}{|l|}{ Man/prof (Reference) } \\
\hline Intermediate/technical & & 1.00 (Reference) & $1.30(1.11,1.49)$ & $1.17(1.04,1.29)$ & $1.09(0.57,1.61)$ & $0.70(0.64,0.75)$ & $0.93(0.52,1.33)$ \\
\hline Routine occupations & & 1.00 (Reference) & $1.83(1.57,2.08)$ & $0.88(0.79,0.97)$ & $1.01(0.53,1.49)$ & $0.51(0.47,0.55)$ & $0.95(0.55,1.34)$ \\
\hline Not known & & 1.00 (Reference) & $1.96(1.66,2.25)$ & $1.87(1.67,2.07)$ & $1.34(0.69,1.99)$ & $1.71(1.59,1.83)$ & $2.79(1.64,3.95)$ \\
\hline Housing tenure $^{3}$ & RRR & & & & & & \\
\hline \multicolumn{8}{|l|}{ Owner (Reference) } \\
\hline Renting & & 1.00 (Reference) & $1.69(1.53,1.84)$ & $1.35(1.26,1.45)$ & $2.92(1.86,3.98)$ & $0.39(0.36,0.41)$ & $0.46(0.31,0.60)$ \\
\hline
\end{tabular}




\begin{tabular}{|c|c|c|c|c|c|c|c|}
\hline & \multirow[t]{2}{*}{$\mathrm{RE}$} & \multicolumn{2}{|c|}{ White } & \multicolumn{2}{|c|}{ Black } & \multicolumn{2}{|c|}{ South Asian } \\
\hline & & Parental care & Non-parental care & Parental care & Non-parental care & Parental care & Non-parental care \\
\hline Other & & 1.00 (Reference) & $1.75(1.39,2.10)$ & $1.06(0.88,1.25)$ & $3.65(1.30,6.00)$ & $0.79(0.69,0.88)$ & $0.36(0.00,0.72)$ \\
\hline Overcrowding $^{1}$ & OR & 1.00 (Reference) & $1.37(1.06,1.68)$ & $2.32(2.00,2.64)$ & $2.06(0.79,3.32)$ & $5.72(5.25,6.20)$ & $9.14(6.04,12.25)$ \\
\hline Lives alone $^{1}$ & OR & 1.00 (Reference) & $1.65(1.35,1.96)$ & $1.69(1.45,1.94)$ & $2.95(1.49,4.42)$ & $1.19(1.03,1.35)$ & 0 \\
\hline Marital status ${ }^{3}$ & RRR & & & & & & \\
\hline Married (Reference) & & & & & & & \\
\hline Previously married & & 1.00 (Reference) & $1.52(1.09,1.95)$ & $0.89(0.47,1.31)$ & $2.62(-0.21,5.45)$ & $0.71(0.53,0.89)$ & $0.34(-0.14,0.83)$ \\
\hline Single & & 1.00 (Reference) & $0.80(0.71,0.89)$ & $2.98(2.59,3.37)$ & $2.24(0.98,3.49)$ & $0.47(0.44,0.51)$ & $0.24(0.17,0.32)$ \\
\hline Number of children ${ }^{4}$ & IRR & 1.00 (Reference) & $1.01(0.90,1.11)$ & $0.89(0.82,0.96)$ & $0.63(0.32,0.95)$ & $0.74(0.69,0.79)$ & $0.55(0.20,0.90)$ \\
\hline Age at first birth ${ }^{5}$ & $B$ & $22.04(21.95,22.13)$ & $\begin{array}{c}21.10(20.81 \\
21.39)\end{array}$ & $21.66(21.42,21.89)$ & $\begin{array}{c}21.45(20.09 \\
22.80)\end{array}$ & $22.92(22.71,23.13)$ & $\begin{array}{c}22.87(21.59 \\
24.16)\end{array}$ \\
\hline
\end{tabular}

${ }^{1}$ Binary logistic regression; ${ }^{2}$ Ordinal logistic regression; ${ }^{3}$ Multinomial logistic regression; ${ }^{4}$ Poisson regression (women only); ${ }^{5}$ Linear regression (parous women only)

Models adjust for gender, age, childhood cohort, and Head of household in childhood's qualifications, marital status, social class and employment status

RE: regression estimate; OR: odds ratio; RRR: relative risk ratio; IRR: incidence rate ratio; B: unstandardized coefficient 
Table S3. Estimates (95\% confidence intervals) for social outcomes regressed on ethnicity by care interaction, age 30-39 follow-up: ONS Longitudinal Study

\begin{tabular}{|c|c|c|c|c|c|c|c|}
\hline & \multirow[t]{2}{*}{$\mathrm{RE}$} & \multicolumn{2}{|c|}{ White } & \multicolumn{2}{|c|}{ Black } & \multicolumn{2}{|c|}{ South Asian } \\
\hline & & Parental care & Non-parental care & Parental care & Non-parental care & Parental care & Non-parental care \\
\hline Self-rated health ${ }^{1}$ & OR & 1.00 (Reference) & $1.90(1.64,2.15)$ & $1.27(1.12,1.42)$ & $1.85(0.94,2.75)$ & $1.14(1.03,1.25)$ & $1.95(1.13,2.77)$ \\
\hline Limiting long-term illness $^{1}$ & OR & 1.00 (Reference) & $1.76(1.49,2.03)$ & $1.11(0.94,1.29)$ & $1.33(0.58,2.09)$ & $0.92(0.80,1.03)$ & $0.84(0.34,1.33)$ \\
\hline$<18$-year qualifications ${ }^{1}$ & $\mathrm{OR}$ & 1.00 (Reference) & $1.75(1.50,2.01)$ & $0.73(0.66,0.81)$ & $0.66(0.36,0.95)$ & $0.48(0.45,0.52)$ & $1.02(0.65,1.40)$ \\
\hline Employment status $^{3}$ & RRR & & & & & & \\
\hline \multicolumn{8}{|l|}{ Employed (Reference) } \\
\hline Unemployed & & 1.00 (Reference) & $1.84(1.46,2.22)$ & $2.08(1.75,2.41)$ & $1.07(0.18,1.96)$ & $1.44(1.24,1.65)$ & $2.32(1.13,3.51)$ \\
\hline In education & & 1.00 (Reference) & $3.63(2.73,4.53)$ & $1.53(1.09,1.97)$ & $3.45(0.66,6.23)$ & $0.97(0.74,1.19)$ & $2.66(0.59,4.72)$ \\
\hline OLF & & 1.00 (Reference) & $1.62(1.39,1.86)$ & $1.09(0.95,1.24)$ & $0.92(0.42,1.42)$ & $1.40(1.26,1.53)$ & $1.63(0.83,2.43)$ \\
\hline Long-term nonemployed $^{1}$ & OR & 1.00 (Reference) & $1.78(1.39,2.16)$ & $0.91(0.70,1.12)$ & $1.56(0.42,2.69)$ & $1.28(1.06,1.49)$ & $1.41(0.25,2.57)$ \\
\hline Social class ${ }^{3}$ & RRR & & & & & & \\
\hline \multicolumn{8}{|l|}{ Man/prof (Reference) } \\
\hline Intermediate/technical & & 1.00 (Reference) & $1.45(1.23,1.67)$ & $0.84(0.75,0.94)$ & $0.59(0.27,0.90)$ & $0.72(0.66,0.78)$ & $1.35(0.81,1.90)$ \\
\hline Routine occupations & & 1.00 (Reference) & $2.00(1.71,2.30)$ & $0.75(0.66,0.83)$ & $0.97(0.51,1.43)$ & $0.43(0.39,0.47)$ & $0.81(0.44,1.17)$ \\
\hline Not known & & 1.00 (Reference) & $3.34(2.68,4.00)$ & $1.55(1.29,1.80)$ & $1.70(0.65,2.75)$ & $1.18(1.03,1.33)$ & $2.82(1.32,4.33)$ \\
\hline Housing tenure $^{3}$ & RRR & & & & & & \\
\hline \multicolumn{8}{|l|}{ Owner (Reference) } \\
\hline Renting & & 1.00 (Reference) & $1.96(1.74,2.18)$ & $1.90(1.72,2.07)$ & $2.68(1.61,3.76)$ & $0.39(0.35,0.42)$ & $0.56(0.34,0.77)$ \\
\hline
\end{tabular}




\begin{tabular}{|c|c|c|c|c|c|c|c|}
\hline & \multirow[t]{2}{*}{$\mathrm{RE}$} & \multicolumn{2}{|c|}{ White } & \multicolumn{2}{|c|}{ Black } & \multicolumn{2}{|c|}{ South Asian } \\
\hline & & Parental care & Non-parental care & Parental care & Non-parental care & Parental care & Non-parental care \\
\hline Other & & 1.00 (Reference) & $2.40(1.77,3.04)$ & $1.25(0.88,1.62)$ & $4.74(1.36,8.13)$ & $0.66(0.49,0.83)$ & $0.43(-0.18,1.03)$ \\
\hline Overcrowding $^{1}$ & OR & 1.00 (Reference) & $1.63(1.20,2.06)$ & $1.72(1.37,2.08)$ & $1.75(0.40,3.10)$ & $3.92(3.46,4.39)$ & $6.00(3.59,8.40)$ \\
\hline Lives alone $^{1}$ & OR & 1.00 (Reference) & $2.25(1.59,2.92)$ & $1.99(1.48,2.50)$ & $5.64(1.16,10.13)$ & $0.58(0.35,0.80)$ & 0 \\
\hline Marital status ${ }^{3}$ & RRR & & & & & & \\
\hline Married (Reference) & & & & & & & \\
\hline Previously married & & 1.00 (Reference) & $1.46(1.20,1.72)$ & $0.96(0.76,1.17)$ & $1.15(0.26,2.05)$ & $0.51(0.43,0.59)$ & $0.59(0.17,1.01)$ \\
\hline Single & & 1.00 (Reference) & $1.28(1.14,1.43)$ & $3.26(2.93,3.59)$ & $2.59(1.46,3.72)$ & $0.43(0.39,0.46)$ & $0.36(0.22,0.50)$ \\
\hline Number of children ${ }^{4}$ & IRR & 1.00 (Reference) & $0.66(0.60,0.72)$ & $0.84(0.79,0.89)$ & $0.38(0.19,0.57)$ & $1.00(0.96,1.05)$ & $0.48(0.27,0.69)$ \\
\hline Age at first birth ${ }^{5}$ & $B$ & $26.64(26.54,26.74)$ & $\begin{array}{c}24.89(24.38 \\
25.41)\end{array}$ & $25.77(25.41,26.13)$ & $\begin{array}{c}24.56(22.39, \\
26.73)\end{array}$ & $27.23(26.96,27.50)$ & $\begin{array}{c}26.84(25.08 \\
28.60)\end{array}$ \\
\hline
\end{tabular}

${ }^{1}$ Binary logistic regression; ${ }^{2}$ Ordinal logistic regression; ${ }^{3}$ Multinomial logistic regression; ${ }^{4}$ Poisson regression (women only); ${ }^{5}$ Linear regression (parous women only)

Models adjust for gender, age, childhood cohort, and Head of household in childhood's qualifications, marital status, social class and employment status

RE: regression estimate; OR: odds ratio; RRR: relative risk ratio; IRR: incidence rate ratio; B: unstandardized coefficient 
Table S4. Estimates (95\% confidence intervals) for social outcomes regressed on ethnicity by care interaction, age $40-49$ follow-up: ONS Longitudinal Study

\begin{tabular}{|c|c|c|c|c|c|c|c|}
\hline & \multirow[t]{2}{*}{ RE } & \multicolumn{2}{|c|}{ White } & \multicolumn{2}{|c|}{ Black } & \multicolumn{2}{|c|}{ South Asian } \\
\hline & & Parental care & Non-parental care & Parental care & Non-parental care & Parental care & Non-parental care \\
\hline Self-rated health ${ }^{1}$ & OR & 1.00 (Reference) & $1.64(1.41,1.87)$ & $1.37(1.20,1.53)$ & $1.85(1.00,2.71)$ & $1.13(0.99,1.27)$ & $2.44(1.48,3.41)$ \\
\hline Limiting long-term illness $^{1}$ & OR & 1.00 (Reference) & $1.87(1.58,2.16)$ & $1.21(1.04,1.39)$ & $1.11(0.50,1.72)$ & $1.06(0.90,1.21)$ & $1.47(0.76,2.18)$ \\
\hline$<18$-year qualifications ${ }^{1}$ & OR & 1.00 (Reference) & $1.25(1.07,1.43)$ & $0.76(0.67,0.84)$ & $0.61(0.34,0.89)$ & $0.64(0.57,0.70)$ & $1.59(0.86,2.31)$ \\
\hline Employment status $^{3}$ & RRR & & & & & & \\
\hline \multicolumn{8}{|l|}{ Employed (Reference) } \\
\hline Unemployed & & 1.00 (Reference) & $1.76(1.28,2.24)$ & $2.07(1.67,2.47)$ & $1.75(0.31,3.18)$ & $1.22(0.93,1.52)$ & $1.86(0.38,3.35)$ \\
\hline In education & & 1.00 (Reference) & $2.42(1.86,2.98)$ & $1.14(0.87,1.42)$ & $1.89(0.30,3.47)$ & $0.85(0.61,1.08)$ & $1.75(0.22,3.28)$ \\
\hline OLF & & 1.00 (Reference) & $1.68(1.36,2.00)$ & $1.03(0.85,1.21)$ & $0.93(0.30,1.56)$ & $1.48(1.25,1.70)$ & $2.28(0.98,3.58)$ \\
\hline Long-term nonemployed $^{1}$ & OR & 1.00 (Reference) & $1.57(1.20,1.94)$ & $0.88(0.68,1.08)$ & $1.21(0.15,2.27)$ & $1.13(0.89,1.38)$ & $2.60(0.93,4.26)$ \\
\hline Social class ${ }^{3}$ & RRR & & & & & & \\
\hline \multicolumn{8}{|l|}{ Man/prof (Reference) } \\
\hline Intermediate/technical & & 1.00 (Reference) & $1.12(0.92,1.31)$ & $0.95(0.83,1.07)$ & $1.01(0.46,1.56)$ & $0.91(0.80,1.02)$ & $2.16(1.13,3.19)$ \\
\hline Routine occupations & & 1.00 (Reference) & $1.42(1.19,1.65)$ & $0.73(0.64,0.83)$ & $0.70(0.32,1.09)$ & $0.51(0.44,0.57)$ & $0.73(0.31,1.16)$ \\
\hline Not known & & 1.00 (Reference) & $2.44(1.82,3.05)$ & $1.48(1.17,1.78)$ & $1.36(0.27,2.45)$ & $1.40(1.11,1.68)$ & $2.77(0.66,4.89)$ \\
\hline Housing tenure $^{3}$ & RRR & & & & & & \\
\hline \multicolumn{8}{|l|}{ Owner (Reference) } \\
\hline Renting & & 1.00 (Reference) & $1.95(1.68,2.22)$ & $1.99(1.77,2.20)$ & $2.62(1.50,3.75)$ & $0.47(0.40,0.54)$ & $0.77(0.36,1.18)$ \\
\hline
\end{tabular}




\begin{tabular}{|c|c|c|c|c|c|c|c|}
\hline & \multirow[t]{2}{*}{$\mathrm{RE}$} & \multicolumn{2}{|c|}{ White } & \multicolumn{2}{|c|}{ Black } & \multicolumn{2}{|c|}{ South Asian } \\
\hline & & Parental care & Non-parental care & Parental care & Non-parental care & Parental care & Non-parental care \\
\hline Other & & 1.00 (Reference) & $2.20(1.27,3.14)$ & $1.81(1.09,2.52)$ & $1.44(-0.52,3.40)$ & $0.93(0.50,1.37)$ & $0.56(-0.58,1.70)$ \\
\hline Overcrowding $^{1}$ & OR & 1.00 (Reference) & $1.02(0.52,1.52)$ & $2.38(1.74,3.02)$ & $0.66(-0.66,1.98)$ & $4.20(3.33,5.06)$ & $11.16(5.72,16.60)$ \\
\hline Lives alone $^{1}$ & OR & 1.00 (Reference) & $3.56(1.53,5.59)$ & $2.19(0.99,3.39)$ & $3.03(-1.00,7.06)$ & $0.31(-0.06,0.68)$ & 0 \\
\hline Marital status ${ }^{3}$ & RRR & & & & & & \\
\hline Married (Reference) & & & & & & & \\
\hline Previously married & & 1.00 (Reference) & $1.44(1.20,1.68)$ & $1.11(0.92,1.30)$ & $1.32(0.43,2.21)$ & $0.56(0.46,0.66)$ & $0.26(0.03,0.50)$ \\
\hline Single & & 1.00 (Reference) & $1.25(1.06,1.44)$ & $3.84(3.41,4.27)$ & $3.81(1.98,5.64)$ & $0.47(0.40,0.55)$ & $0.25(0.06,0.44)$ \\
\hline Number of children ${ }^{4}$ & IRR & 1.00 (Reference) & $0.56(0.49,0.62)$ & $0.91(0.86,0.96)$ & $0.42(0.18,0.67)$ & $1.10(1.04,1.15)$ & $0.34(0.11,0.57)$ \\
\hline Age at first birth ${ }^{5}$ & $B$ & $28.80(28.64,28.95)$ & $\begin{array}{c}26.73(26.03, \\
27.42)\end{array}$ & $\begin{array}{c}28.34(27.85, \\
28.84)\end{array}$ & $\begin{array}{c}25.35(22.54, \\
28.16)\end{array}$ & $29.27(28.83,29.71)$ & $\begin{array}{c}29.21(26.06 \\
32.36)\end{array}$ \\
\hline
\end{tabular}

${ }^{1}$ Binary logistic regression; ${ }^{2}$ Ordinal logistic regression; ${ }^{3}$ Multinomial logistic regression; ${ }^{4}$ Poisson regression (women only); ${ }^{5}$ Linear regression (parous women only)

Models adjust for gender, age, childhood cohort, and Head of household in childhood's qualifications, marital status, social class and employment status

RE: regression estimate; OR: odds ratio; RRR: relative risk ratio; IRR: incidence rate ratio; B: unstandardized coefficient 
Table S5. Average marginal effects ${ }^{1}$ for social outcomes regressed on UK-born and non-parental care grouping interaction models: ONS Longitudinal Study

\begin{tabular}{|c|c|c|c|c|c|c|}
\hline & \multicolumn{2}{|c|}{ Age $20-29$ years } & \multicolumn{2}{|c|}{ Age $30-39$ years } & \multicolumn{2}{|c|}{ Age $40-49$ years } \\
\hline & UK-born & Non-UK born & UK-born & Non-UK born & UK-born & Non-UK born \\
\hline Self-rated health & $0.07(0.05,0.09)$ & $0.05(-0.03,0.13)$ & $0.10(0.07,0.12)$ & $0.10(0.02,0.18)$ & $0.09(0.06,0.11)$ & $0.09(0.02,0.16)$ \\
\hline Limiting long-term illness & $0.04(0.02,0.05)$ & $0.01(-0.03,0.04)$ & $0.05(0.03,0.06)$ & $0.01(-0.03,0.05)$ & $0.07(0.05,0.10)$ & $0.06(0.00,0.13)$ \\
\hline$<18$-year qualifications & $0.09(0.07,0.11)$ & $0.09(0.03,0.14)$ & $0.09(0.07,0.12)$ & $0.08(0.02,0.14)$ & $0.04(0.01,0.07)$ & $0.17(0.09,0.24)$ \\
\hline \multicolumn{7}{|l|}{ Employment status } \\
\hline Employed & $-0.09(-0.11,-0.07)$ & $0.01(-0.05,0.07)$ & $-0.10(-0.12,-0.08)$ & $-0.04(-0.10,0.02)$ & $-0.10(-0.12,-0.07)$ & $-0.03(-0.10,0.04)$ \\
\hline Unemployed & $0.04(0.02,0.05)$ & $0.02(-0.02,0.05)$ & $0.02(0.01,0.03)$ & $0.01(-0.02,0.04)$ & $0.02(0.00,0.03)$ & $0.00(-0.03,0.02)$ \\
\hline In education & $0.00(-0.01,0.01)$ & $-0.03(-0.05,0.00)$ & $0.03(0.02,0.04)$ & $0.02(-0.01,0.05)$ & $0.04(0.02,0.05)$ & $0.02(-0.02,0.06)$ \\
\hline OLF & $0.05(0.04,0.07)$ & $0.00(-0.04,0.05)$ & $0.05(0.03,0.07)$ & $0.01(-0.04,0.06)$ & $0.04(0.02,0.06)$ & $0.02(-0.04,0.07)$ \\
\hline Long-term nonemployed & $0.01(0.00,0.02)$ & $0.01(-0.01,0.04)$ & $0.02(0.01,0.03)$ & $0.01(-0.01,0.04)$ & $0.03(0.01,0.05)$ & $0.00(-0.04,0.03)$ \\
\hline \multicolumn{7}{|l|}{ Social class ${ }^{3}$} \\
\hline Managerial/professional & $-0.07(-0.08,-0.05)$ & $-0.10(-0.14,-0.05)$ & $-0.11(-0.13,-0.09)$ & $-0.14(-0.20,-0.08)$ & $-0.06(-0.08,-0.03)$ & $-0.14(-0.21,-0.06)$ \\
\hline Intermediate/technical & $-0.03(-0.05,-0.01)$ & $-0.01(-0.07,0.05)$ & $-0.02(-0.04,0.00)$ & $0.04(-0.03,0.11)$ & $-0.02(-0.04,0.01)$ & $0.11(0.02,0.19)$ \\
\hline Routine occupations & $0.06(0.04,0.08)$ & $0.10(0.02,0.17)$ & $0.07(0.05,0.10)$ & $0.08(0.01,0.16)$ & $0.04(0.01,0.07)$ & $0.01(-0.07,0.09)$ \\
\hline Not known & $0.03(0.02,0.05)$ & $0.01(-0.04,0.06)$ & $0.05(0.04,0.07)$ & $0.02(-0.01,0.05)$ & $0.03(0.02,0.05)$ & $0.02(-0.01,0.06)$ \\
\hline
\end{tabular}




\begin{tabular}{|c|c|c|c|c|c|c|}
\hline & \multicolumn{2}{|c|}{ Age $20-29$ years } & \multicolumn{2}{|c|}{ Age $30-39$ years } & \multicolumn{2}{|c|}{ Age $40-49$ years } \\
\hline & UK-born & Non-UK born & UK-born & Non-UK born & UK-born & Non-UK born \\
\hline \multicolumn{7}{|l|}{ Housing tenure } \\
\hline Owner occupier & $-0.12(-0.14,-0.10)$ & $-0.02(-0.10,0.05)$ & $-0.14(-0.16,-0.12)$ & $-0.09(-0.17,-0.01)$ & $-0.13(-0.15,-0.10)$ & $-0.06(-0.14,0.03)$ \\
\hline Renting & $0.11(0.09,0.13)$ & $0.05(-0.03,0.12)$ & $0.12(0.10,0.14)$ & $0.07(-0.01,0.15)$ & $0.12(0.09,0.14)$ & $0.06(-0.02,0.14)$ \\
\hline Other & $0.01(0.00,0.02)$ & $-0.02(-0.05,0.00)$ & $0.02(0.01,0.03)$ & $0.02(-0.01,0.05)$ & $0.01(0.00,0.02)$ & $0.00(-0.02,0.01)$ \\
\hline Overcrowding & $0.01(0.00,0.02)$ & $0.00(-0.01,0.02)$ & $0.01(0.00,0.02)$ & $0.02(0.00,0.05)$ & $0.00(-0.01,0.01)$ & $0.03(0.00,0.05)$ \\
\hline Lives alone & $0.02(0.01,0.03)$ & $-0.01(-0.03,0.01)$ & $0.02(0.01,0.03)$ & $0.01(-0.01,0.03)$ & $0.01(0.00,0.01)$ & $0.01(-0.01,0.02)$ \\
\hline \multicolumn{7}{|l|}{ Marital status } \\
\hline Currently married & $0.03(0.02,0.05)$ & $0.08(0.03,0.14)$ & $-0.06(-0.08,-0.03)$ & $0.00(-0.08,0.07)$ & $-0.06(-0.09,-0.03)$ & $0.00(-0.08,0.08)$ \\
\hline Previously married & $0.01(0.00,0.02)$ & $0.00(-0.01,0.01)$ & $0.03(0.01,0.04)$ & $-0.04(-0.07,-0.02)$ & $0.04(0.02,0.06)$ & $-0.04(-0.09,0.01)$ \\
\hline Single & $-0.04(-0.06,-0.02)$ & $-0.08(-0.14,-0.02)$ & $0.03(0.01,0.06)$ & $0.05(-0.03,0.12)$ & $0.01(-0.01,0.04)$ & $0.04(-0.03,0.11)$ \\
\hline $\begin{array}{l}\text { Number of children (women } \\
\text { only) }\end{array}$ & $0.00(-0.05,0.04)$ & $-0.30(-0.46,-0.14)$ & $-0.46(-0.54,-0.37)$ & $-1.06(-1.29,-0.83)$ & $-0.76(-0.87,-0.65)$ & $-1.60(-1.85,-1.35)$ \\
\hline $\begin{array}{l}\text { Age at first child (parous } \\
\text { women only) }\end{array}$ & $-0.90(-1.16,-0.63)$ & $0.51(-1.30,2.31)$ & $-1.74(-2.22,-1.26)$ & $0.86(-1.41,3.12)$ & $-2.04(-2.71,-1.38)$ & $-2.87(-4.03,-1.70)$ \\
\hline
\end{tabular}

${ }^{1}$ Average marginal effect = average difference between predicted effect if in non-parental care and predicted effect if in parental care, leaving all other covariates as observed.

Outcomes in bold are significant at $p<0.05$ 